University of New Hampshire

University of New Hampshire Scholars' Repository

Faculty Publications

$11-12-2002$

\title{
Large-scale hydro-climatology of the terrestrial Arctic drainage system
}

\author{
Mark C. Serreze \\ University of Colorado, Boulder \\ David H. Bromwich \\ Ohio State University \\ Martyn P. Clark \\ University of Colorado \\ Andrew J. Etringer \\ University of Colorado \\ Tingjun Zhang \\ University of Colorado
}

See next page for additional authors

Follow this and additional works at: https://scholars.unh.edu/faculty_pubs

Comments

This is an article published by AGU in Journal of Geophysical Research: Atmospheres in 2002, available online:

https://dx.doi.org/10.1029/2001JD000919

\section{Recommended Citation}

Serreze, Mark C., David H. Bromwich, Martyn P. Clark, Andrew J. Etringer, Tinjung Zhang and Richard Lammers (2002) Large-scale Hydro-climatology of the Terrestrial Arctic Drainage System, Journal of Geophysical Research, 107, 8160, doi:10.1029/2001JD000919. Also printed in a collected papers volume, Arctic Transitions in the Land-Atmosphere System, 2003, by the American Geophysical Union.

This Article is brought to you for free and open access by University of New Hampshire Scholars' Repository. It has been accepted for inclusion in Faculty Publications by an authorized administrator of University of New Hampshire Scholars' Repository. For more information, please contact Scholarly.Communication@unh.edu. 


\section{Authors}

Mark C. Serreze, David H. Bromwich, Martyn P. Clark, Andrew J. Etringer, Tingjun Zhang, and Richard B. Lammers 


\title{
Large-scale hydro-climatology of the terrestrial Arctic drainage system
}

\author{
Mark C. Serreze, ${ }^{1}$ David H. Bromwich, ${ }^{2}$ Martyn P. Clark, ${ }^{1}$ Andrew J. Etringer, ${ }^{1}$ \\ Tingjun Zhang, ${ }^{1}$ and Richard Lammers ${ }^{3}$ \\ Received 5 June 2001; revised 7 December 2001; accepted 10 December 2001; published 12 November 2002.
}

[1] The large-scale hydro-climatology of the terrestrial Arctic drainage system is examined, focusing on the period 1960 onward. Special attention is paid to the Ob, Yenisey, Lena, and Mackenzie watersheds, which provide the bulk of freshwater discharge to the Arctic Ocean. Station data are used to compile monthly gridded time series of gaugecorrected precipitation $(P)$. Gridded time series of precipitation minus evapotranspiration $(P-\mathrm{ET})$ are calculated from the moisture flux convergence using NCEP reanalysis data. Estimates of ET are obtained as a residual. Runoff $(R)$ is obtained from available discharge records. For long-term water-year means, $P$-ET for the Yenisey, Lena, and Mackenzie watersheds is $16-20 \%$ lower than the observed runoff. In the Ob watershed, the two values agree within $9 \%$. Given the uncertainties in $P$-ET, we consider the atmospheric and surface water budgets to be reasonably closed. Compared to the other three basins, the mean runoff ratio $(R / P)$ is lower in the $\mathrm{Ob}$ watershed, consistent with the high fraction of annual precipitation lost through ET. All basins exhibit summer maxima in $P$ and minima in $P$-ET. Summer $P$-ET in the $\mathrm{Ob}$ watershed is negative due to high ET rates. For large domains in northern Eurasia, about $25 \%$ of July precipitation is associated with the recycling of water vapor evapotranspirated within each domain. This points to a significant effect of the land surface on the hydrologic regime. Variability in $P$ and $P-$ ET has generally clear associations with the regional atmospheric circulation. A strong link with the Urals trough is documented for the Ob. Relationships with indices of the Arctic Oscillation and other teleconnections are generally weak. Water-year time series of runoff and $P$-ET are strongly correlated in the Lena watershed only, reflecting extensive permafrost. Cold-season runoff has increased in the Yenisey and Lena watersheds. This is most pronounced in the Yenisey watershed, where runoff has also increased sharply in spring, decreased in summer, but has increased for the year as a whole. The mechanisms for these changes are not entirely clear. While they fundamentally relate to higher air temperatures, increased winter precipitation, and strong summer drying, we speculate links with changes in active layer thickness and thawing permafrost. INDEX TERMS: 1833 Hydrology: Hydroclimatology; 1836 Hydrology: Hydrologic budget (1655); 1860 Hydrology: Runoff and streamflow; 1854 Hydrology: Precipitation (3354); 1818 Hydrology: Evapotranspiration

Citation: Serreze, M. C., D. H. Bromwich, M. P. Clark, A. J. Ertringer, T. Zhang, and R. Lammers, Large-scale hydro-climatology of the terrestrial Arctic drainage system, J. Geophys. Res., 107, 8160, doi:10.1029/2001JD000919, 2002. [printed 108(D2), 2003]

\section{Introduction}

[2] The hydro-climatology of the Arctic terrestrial drainage system plays an important role in the climate system. The primary freshwater source to the Arctic Ocean of

\footnotetext{
${ }^{1}$ Cooperative Institute for Research in Environmental Sciences, University of Colorado, Boulder, Colorado, USA.

${ }^{2}$ Byrd Polar Research Center, Ohio State University, Columbus, Ohio, USA.

${ }^{3}$ Water Systems Analysis Group, University of New Hampshire, Durham, New Hampshire, USA.

Copyright 2002 by the American Geophysical Union. 0148-0227/02/2001JD000919
}

about $35 \mathrm{~cm}$ per year is river runoff [Aagaard and Carmack, 1989]. Runoff influences ocean salinity and sea ice conditions [McDonald et al., 1999; Steele and Boyd, 1998], which can impact on freshwater fluxes through the Fram Strait and Greenland Sea into the North Atlantic. The degree of surface freshening in the North Atlantic is thought to influence the global thermohaline circulation [Broecker, 1997]. Changes in the terrestrial hydrologic cycle may alter soil moisture and plant communities with consequent climate feedbacks. Arctic soils and wetlands are potentially significant sources of global carbon dioxide and methane. Fluxes of these gases respond sensitively to altered soil moisture and temperature [Oechel et al., 1993].

[3] Information on basic aspects of the terrestrial hydroclimatology, such as seasonal cycles and spatiotemporal 


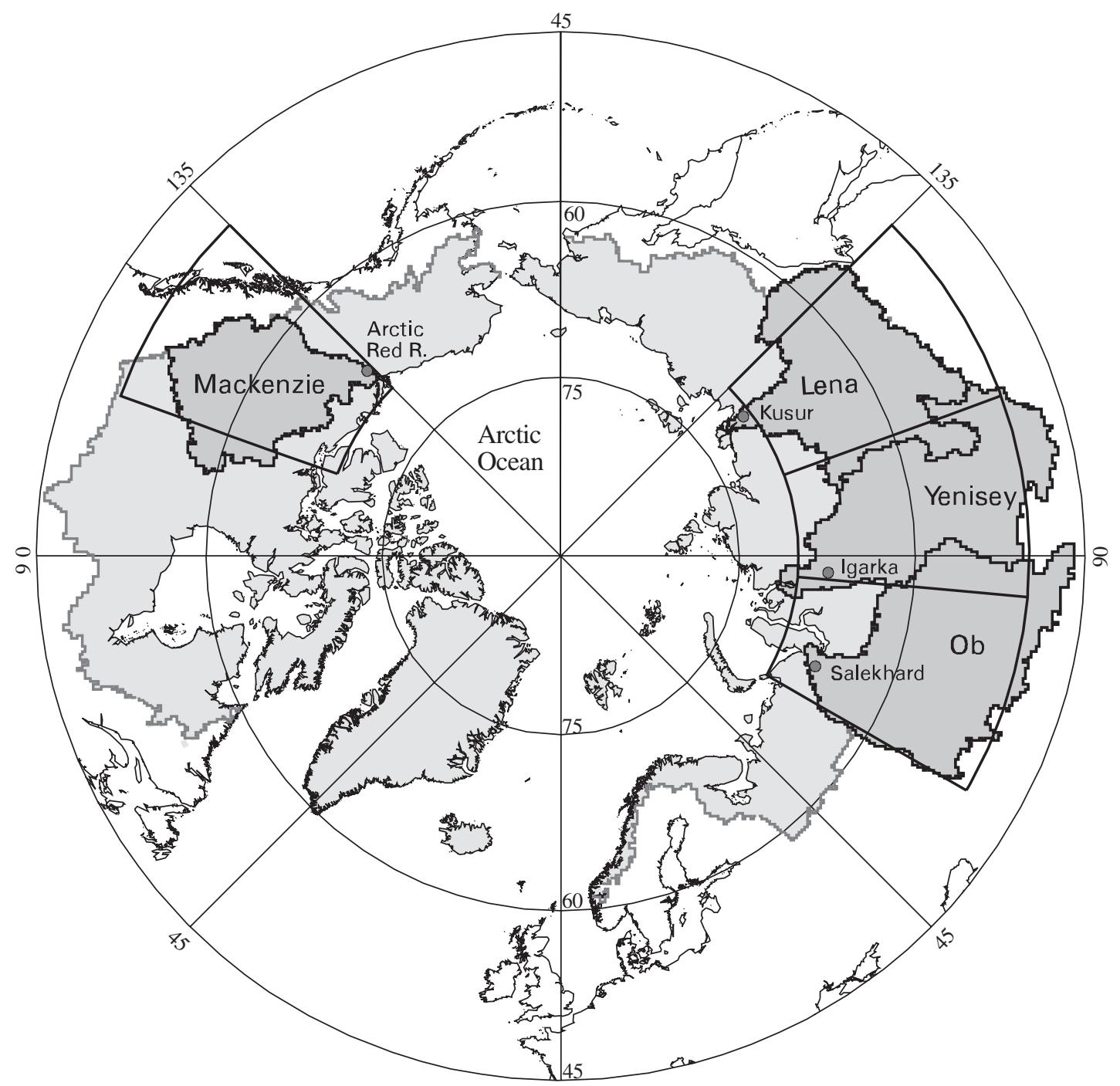

Figure 1. Definition of the Arctic drainage (total shaded area), showing the boundaries of the $\mathrm{Ob}$, Yenisey, Lena and Mackenzie basins (dark shading). Also shown are the locations of the gauging stations used in this study and the four simplified domains for assessing precipitation recycling.

variability of precipitation $(P)$, evapotranspiration (ET), effective precipitation $(P-\mathrm{ET})$ and their links with river discharge is surprisingly limited. Better understanding terrestrial hydro-climatic processes is especially relevant given the pronounced changes observed in northern high latitude lands during recent decades. These include increases in winter and spring air temperature, reductions in snow cover and warming of soils and permafrost [Serreze et al., 2000]. Grabs et al. [2000] and Yang et al. [2002] report on recent increases in Siberian river discharge during winter which they suggest relate to winter and spring warming.

[4] The present paper examines the large-scale hydroclimatology of the terrestrial Arctic drainage system (Figure 1). The Arctic drainage is defined as land areas emptying into the Arctic Ocean and areas draining into Hudson Bay, James Bay, Hudson Strait and the Bering Strait. The Yukon and Anadyr rivers drain into the northern Bering Sea but supply significant freshwater to the Arctic
Ocean via northward flow though the Bering Strait. They are therefore taken as part of the Arctic drainage.

[5] Our study draws from station archives to compile monthly gridded and regionally averaged time series of gauge-corrected precipitation. Time series of $P-\mathrm{ET}$ are calculated from the moisture flux convergence using wind and humidity fields from the National Centers for Environmental Prediction/National Center for Atmospheric Research (NCEP/NCAR) reanalysis [Kalnay et al., 1996; Kistler et al., 2001]. Estimates of ET are obtained as a residual from $P$ and $P$-ET. Following examination of mean fields over the Arctic drainage, attention turns to the $\mathrm{Ob}$, Yenisey, Lena and Mackenzie. These four rivers collectively provide the bulk of freshwater discharge to the Arctic Ocean. Means, interannual variability and trends in $P, P-\mathrm{ET}$, ET and precipitation recycling are examined in the context of atmospheric circulation, runoff, surface air temperature, permafrost extent and soil temperature. Our study focuses on the period from 1960 


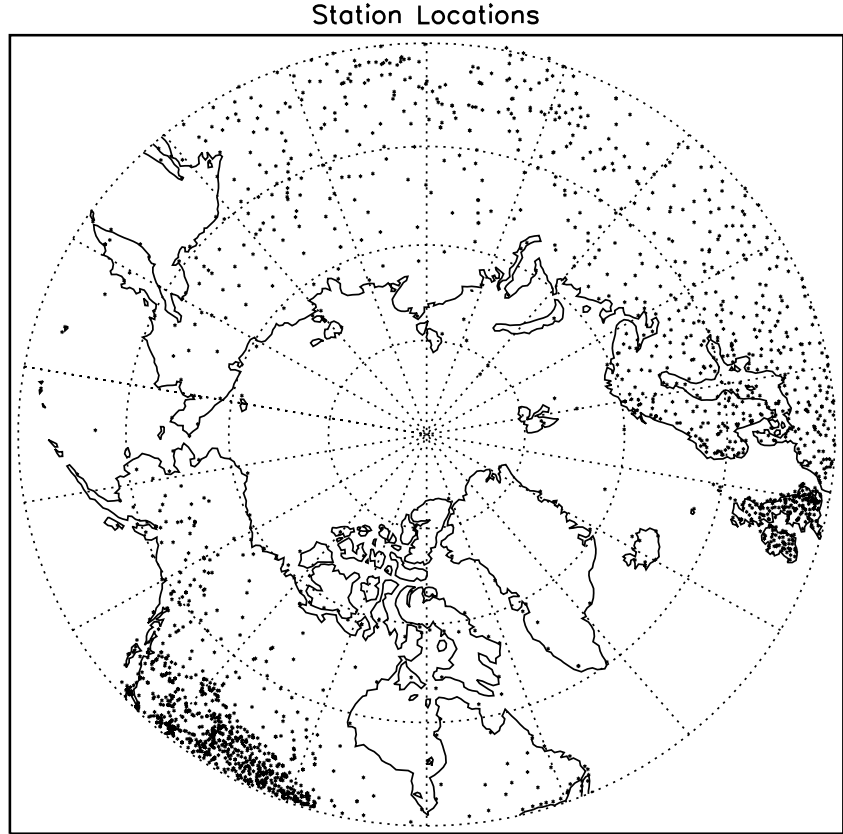

Figure 2. Distribution of precipitation measuring stations north of $50^{\circ} \mathrm{N}$.

onwards. Earlier data from the NCEP reanalysis are less reliable because of sparse assimilation data [Kistler et al., 2001].

\section{Data Sets}

\subsection{Precipitation}

[6] Assessing precipitation in northern high latitudes is difficult due to the sparse station network (Figure 2). These problems are becoming more acute due to closure of many stations in the Former Soviet Union (FSU) and Canada in the early 1990s. Canada is also seeing a trend toward the use of automated stations. Perhaps more fundamental are inhomogeneities in time series associated with undercatch of solid precipitation, wetting and evaporation losses, neglect of trace amounts and differences in observing methods.

[7] The World Meteorological Organization (WMO) Solid Precipitation Intercomparison Project [Goodison et al., 1998; Yang et al., 2001] concluded that wind speed is the most important environmental variable influencing gauge catch efficiency. Different gauge and shield combinations used in high latitudes introduce variations in catch efficiency which are especially pronounced for high wind speeds. Errors can reach $50-100 \%$ in cold, windy environments. This has created artificial discontinuities in coldregion precipitation within countries and across international borders [Yang et al., 2001].

[8] Numerous efforts have been made to provide data sets with bias adjustments. Corrections in most archives [e.g., Legates and Willmott, 1990; Groisman et al., 1991] are climatological in the sense that they represent constant adjustments to raw monthly precipitation totals. Corrections are site-specific and require information on gauge type, winds and site conditions. At present, there is little com- munity agreement regarding correction techniques and adjusted time series have only been compiled on a regional basis. What is needed is a "best faith" effort to compile a corrected archive for the entire Arctic. In the absence of such a data set, we combine monthly precipitation records from several different archives. Discussion of these data sets is deferred to Appendix A.

[9] The station time series were gridded to the $25 \times 25$ $\mathrm{km}$ National Snow and Ice Data Center (NSIDC) north polar equal-area scalable earth (EASE) grid [Armstrong and Brodzik, 1995] lying within the Arctic drainage. Vorosmarty et al. [2000] developed a global digital river network on a $0.5 \times 0.5$ degree grid $(\mathrm{STN}-30)$. The domain shown in Figure 1 is based on a recent version of the river network translated to the $25 \times 25 \mathrm{~km}$ EASE grid. Interpolation techniques are described in Appendix A.

[10] Gridded time series for the entire Arctic drainage were prepared for the period 1960-1989. For Eurasia, where updated station records are available, fields were prepared for 1960-1999. Gridded fields for Eurasia are less accurate for the 1990s as they are based on fewer stations than earlier decades (Appendix A). Even for 1960-1989 (for which station coverage is best) temporal inhomogeneities can be introduced in the gridded time series as stations enter or drop out of the network. Our time series analyses are restricted to basin averages, acting to mitigate these problems.

\subsection{Precipitation Minus Evapotranspiration (P-ET)}

[11] Fields of $P$-ET (1960-1999) are computed from the vertically integrated vapor flux convergence adjusted by the time change in precipitable water. On monthly timescales, $P$-ET is dominated by the flux convergence term. Cullather et al. [2000] and Rogers et al. [2001] provide further background and discuss applications to studies of the Arctic moisture budget. NCEP archives vertical integrals of monthly mean zonal and meridional moisture fluxes as well as precipitable water, simplifying the calculations. The integrals are based on 6-hourly values at sigma levels on a $2.5 \times 2.5$ degree grid. Calculations based on sigma coordinate data do not suffer from mass balance errors that can arise during the conversion from sigma to pressure level data. The intent behind reanalysis is to compile global, analyzed and forecasted fields using a "frozen" data assimilation/forecast system. This eliminates pseudo climate signals introduced by changes in model physics. Temporal discontinuities are still inevitable due to changes in the amount and quality of assimilation data [Kalnay et al., 1996; Kistler et al., 2001]. Assimilation data consist primarily of "free-air" variables such as temperature, wind and humidity profiles obtained from rawinsonde ascents and satellite retrievals. It should be noted that the rawinsonde network over Arctic and sub-Arctic land areas is relatively dense [Serreze et al., 1995]. The computed $P$-ET data for 1960-1999 were transformed to the EASE grid using a simple Cressman [1959] interpolation. ET was simply calculated as a residual from gridded $P$ and $P-$ ET

[12] Six-hour forecasts of $P$ and ET are standard products from the NCEP reanalysis. Unlike $P$-ET computed from analyzed wind and humidity fields, forecasted $P$ and ET are purely model outputs and suffer from deficiencies in model 
physics and parameterizations. While there is useful information in the temporal variability of the NCEP precipitation forecasts [Serreze et al., 2001a] (M. C. Serreze et al., Monitoring precipitation over the Arctic terrestrial drainage system: Data requirements, shortcomings and applications of atmospheric reanalysis, submitted to Journal of Hydrometeorology, 2003, hereinafter referred to as Serreze et al., submitted manuscript, 2003), the raw values are not considered accurate enough for direct hydrologic applications [Serreze and Hurst, 2000; Cullather et al., 2000].

\subsection{River Discharge}

[13] Monthly discharge data for the Ob, Yenisey, Lena and Mackenzie (Figure 1) were obtained from R-ArcticNET, a digital archive (CD-ROM) for the Arctic drainage [Lammers et al., 2001]. We use monthly mean gauge records for the $\mathrm{Ob}$ at Salekhard, the Yenisey at Igarka, the Lena at Kusur, and the Mackenzie at Arctic Red River. These represent the gauging stations nearest to the mouths of the four rivers (Figure 1). Discharge was converted into runoff by dividing the discharge by the basin area. Records for the Eurasian basins are available for the entire period of our study (1960-1999). A shorter record (October 1972 through December 1997) is available for the Mackenzie.

\subsection{Ancillary Data}

[14] The International Permafrost Association (IPA) published a pan-Arctic map of permafrost and ground-ice conditions [Brown et al., 1997]. A digital version was prepared for distribution as the Circumpolar Active-Layer Permafrost System (CAPS) CD-ROM [IPA, 1998; Brown et al., 1998, CD-ROM available from the NSIDC, nside@ kryos.colorado.edu]. Zhang et al. [1999] converted the map to the NSIDC EASE grid at a $25 \mathrm{~km}$ resolution. The IPA map includes information on permafrost extent and continuity, ground ice content and the northern limit of trees subsea permafrost. Permafrost thickness and temperature at the base of the layer of annual temperature fluctuation are also included at selected areas and sites, especially over Russia.

[15] Time series from several stations are used to examine trends in soil temperatures at $20 \mathrm{~cm}, 40 \mathrm{~cm}$, and $80 \mathrm{~cm}$ depth. The sites and record lengths are: Nyaksimvol $\left(62.4^{\circ} \mathrm{N}, 60.9^{\circ} \mathrm{E}\right.$ in the $\mathrm{Ob}$ basin) from 1960 through 1990 ; Norilsk $\left(69.3^{\circ} \mathrm{N}, 88.3^{\circ} \mathrm{E}\right.$ in the Yenisey basin) from 1967 through 1990; and Bestyachskaya Zveroferma $\left(65.3^{\circ} \mathrm{N}, 124.2^{\circ} \mathrm{E}\right.$ in the Lena basin) from 1966 through 1994. Data collection is summarized by Gilichinsky et al. [1998], Zhang et al. [2001] and instruction manuals of the State Committee of the USSR for Hydrometeorology and Environmental Control [1985]. These represent the only stations lying within the Eurasian watersheds having relatively long records that overlap with the other variables in our study. We have no such time series for the Mackenzie.

[16] Relationships between $P$-ET and atmospheric variability are examined using analyzed fields of monthly 500 $\mathrm{hPa}$ height and sea level pressure (SLP) from the NCEP reanalysis, as well as indices of various atmospheric teleconnection patterns. Use is also made of fields of climatological monthly surface air temperature from Willmott and Robeson [1995], based on interpolation of GHCN data with adjustments for topography, satellite-derived snow cover based on weekly NOAA snow charts [cf. Robinson et al.,
1993] and satellite-derived land cover based on the United States Geological Service (USGS) Global Land Cover Characterization database. All of these data sets have been transformed to the $25 \times 25 \mathrm{~km}$ EASE grid.

\section{Mean Budget Components \\ 3.1. Spatial Fields}

[17] Figures 3-5 show mean fields of $P$, computed $P$-ET and ET over the Arctic drainage for alternate months. Results are based on the 30-year period 1960-1989 for which the station precipitation database is most robust. Precipitation values over central Greenland rely on interpolation from coastal sites (Figure 2) and should be viewed cautiously.

[18] Cold-season precipitation (Figure 3) (November through April) is meager (below $20 \mathrm{~mm}$ and locally less than $10 \mathrm{~mm}$ ) over much of eastern Eurasia, northern Alaska and Northern Canada. Here anticyclonic conditions tend to prevail and precipitable water is low. High winter precipitation totals along the southeast coast of Greenland and the Scandinavian coast result from frequent cyclone activity associated with the Icelandic Low and North Atlantic cyclone track and orographic uplift of moist air masses These Atlantic-side maxima weaken during summer in accord with the seasonal decline in Atlantic-side cyclone frequency and intensity.

[19] There is a summertime precipitation maximum over most land areas. For parts of Eurasia and Canada, July precipitation increases by a factor of seven from January totals. The onset of the summer pattern is seen as a strong transition between May and June. The summer maximum over land reflects: 1) a tendency for more frequent cyclone activity as compared with winter: 2) reductions in static stability after melt of the snow cover and a seasonal increase in water vapor content promoting convective precipitation [Serreze and Hurst, 2000]; 3) a high frequency of frontal activity along Eurasia and Alaska (the summer "Arctic Frontal Zone"), related to heating contrasts between the snow-free land and cold Arctic Ocean [Serreze et al., 2001a].

[20] Spatial variability in cold-season $P$-ET (Figure 4) is more subdued as compared to precipitation. Cold-season $P-$ ET is maximized along the southeast coast of Greenland and western North America. $P$-ET tends to be at a minimum during summer over much of Eurasia and Canada. During July, $P-$ ET is negative over large areas. Since ET exceeds $P$, it is apparent that although $P$ is at its seasonal maximum, there is a net surface drying. This is in sharp contrast to the Arctic Ocean, where both $P$ and $P$-ET peak during summer [Serreze et al., 1995].

[21] As discussed, ET is calculated as a residual from $P$ and computed $P$-ET (Figure 5). Estimated ET for summer months is largest $(>70 \mathrm{~mm})$ over west-central Eurasia and the southern part of the North American domain. Monthly summer totals over northern Canada and northeast Eurasia are much smaller $(10-40 \mathrm{~mm})$. For winter months, the residual estimated of ET is slightly negative over parts of Eurasia and Canada. At face value, this implies net deposition of water vapor at the surface. While rime deposition occurs in these areas, it is unlikely to result in climatological values of negative ET. Indeed, previous studies have shown 


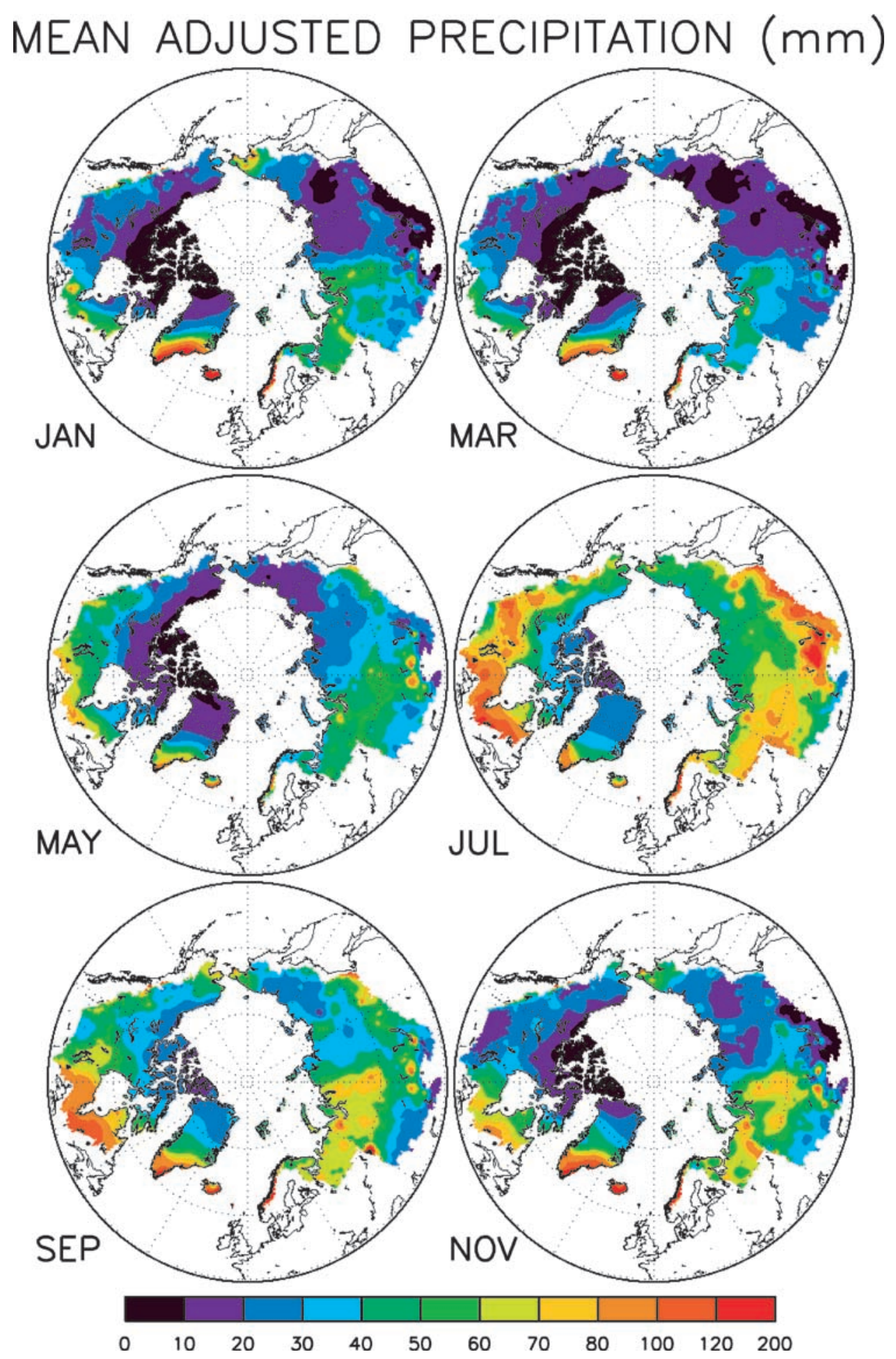

Figure 3. Mean-monthly precipitation $(P)$ for the Arctic drainage, based on data from 1960 through 1989 (mm). Plots are shown for alternate months.

that sublimation during blowing snow events can represent a significant loss of snow mass during winter [Hinzman et al., 1996; Kane et al., 1991].

[22] The negative ET rates indicate that either (or): a) bias adjustments not withstanding, estimated winter $P$ is still too low; b) calculated $P$-ET is too large. There is reason to think that the problem lies with precipitation. Monitoring stations tend to be biased to low elevation areas (i.e., valley sites) where precipitation amounts are likely to be lower. This could produce a negative bias in estimated regional precipitation, largest in areas with complex topography. Such areas include central to eastern Eurasia, western Canada, Alaska and the Canadian Arctic Archipelago. Different techniques were used to compile the fields of $P$ and $P$-ET (interpolation of fairly sparse station data versus reprojection of a latitude/longitude grid). The different 


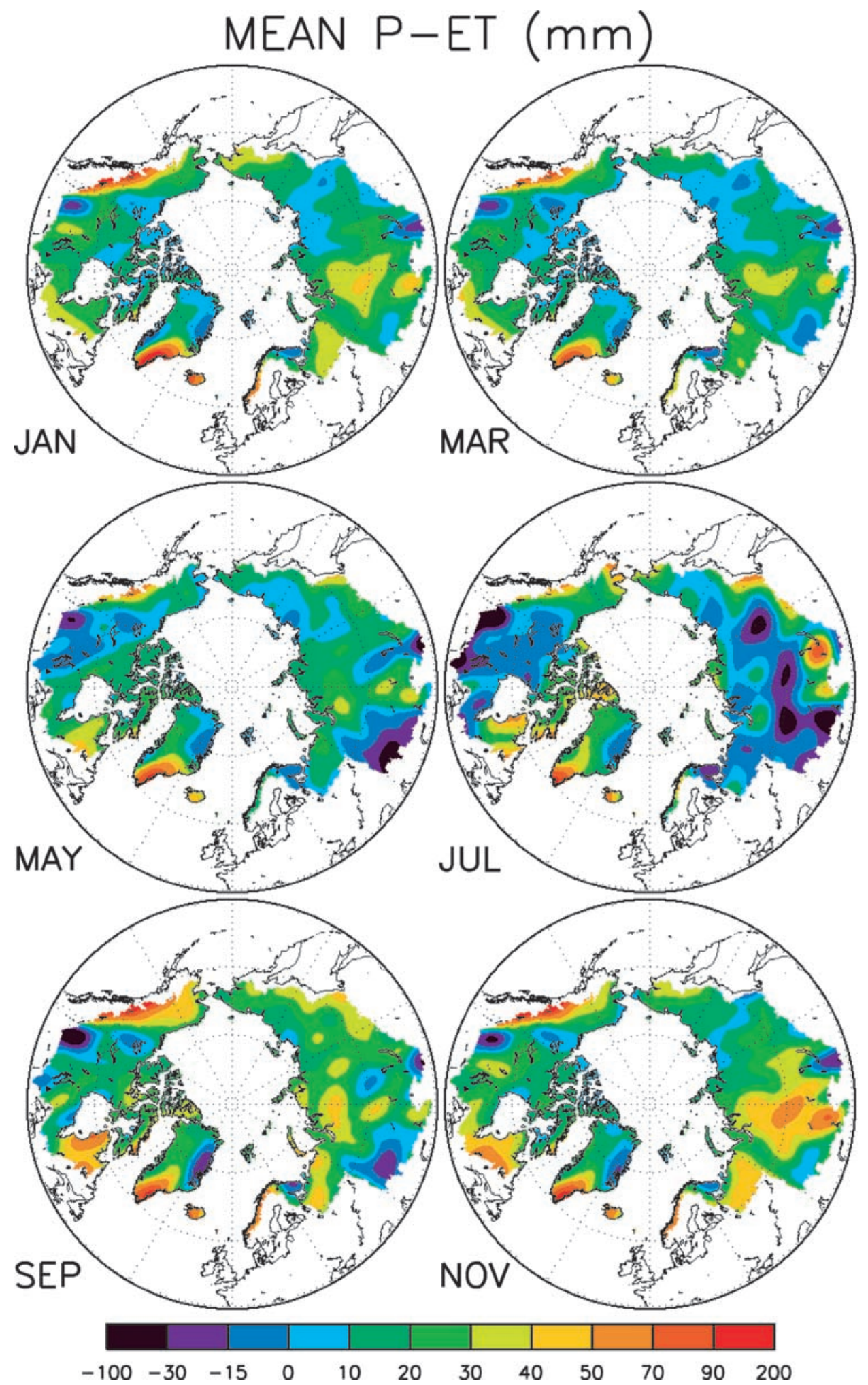

Figure 4. Mean-monthly precipitation minus evapotranspiration $(P-\mathrm{ET})$ for the Arctic drainage, based on data from 1960 through 1989 (mm). Plots are shown for alternate months.

inherent scales of the two fields will have some influence on the computed ET fields.

\subsection{Seasonal Cycles and Water-Year Means}

[23] Figure 6 summarizes mean seasonal cycles of $P$, $P$-ET and ET for the $\mathrm{Ob}$, Yenisey, Lena and Mack- enzie basins. Results are again based on the 30-year period 1960-1989. The monthly values are simple averages of the data at all EASE grid points located within each basin. The seasonal cycles are expressed in terms of the water year, taken as 1 October through 30 September. 


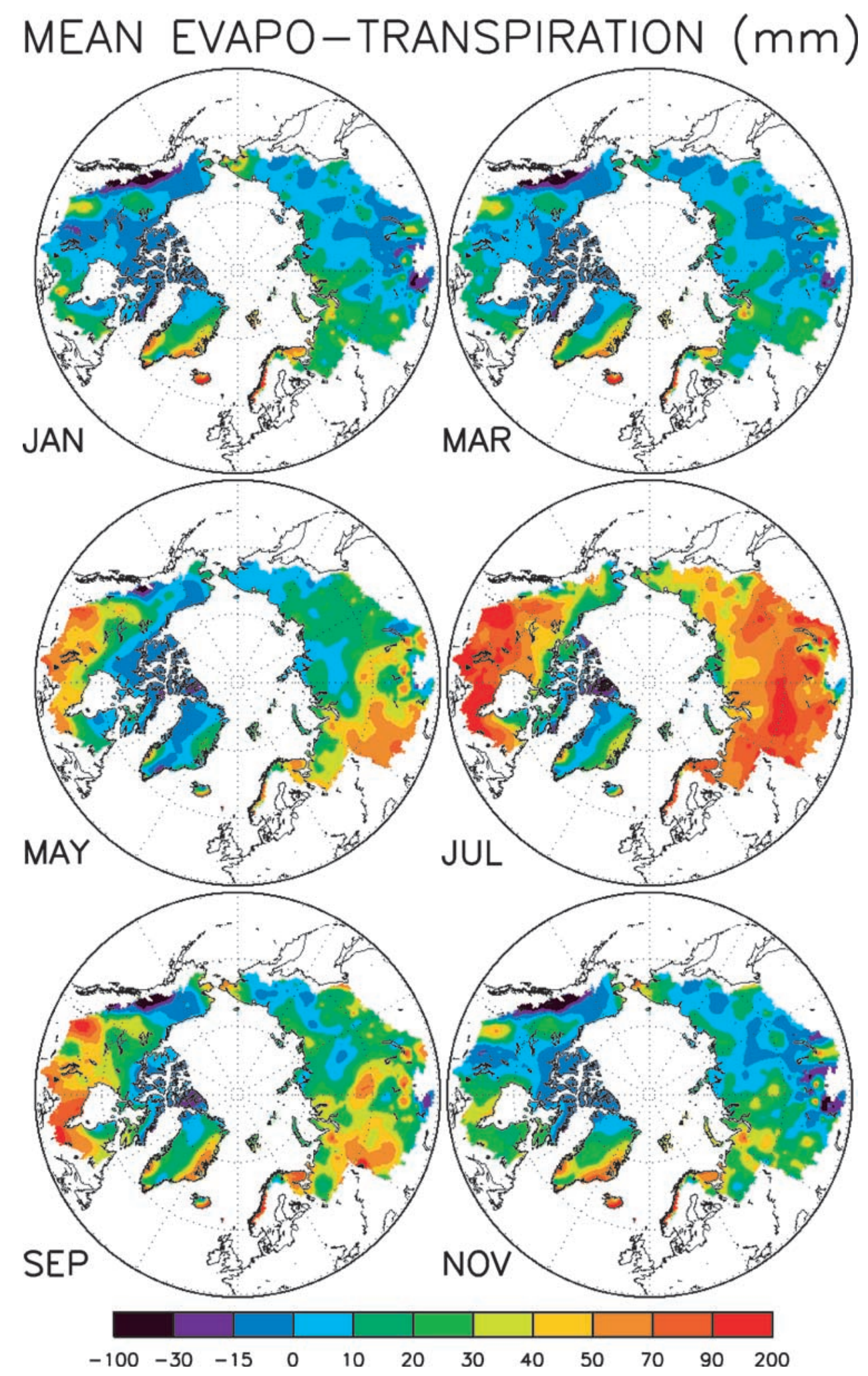

Figure 5. Mean-monthly evapotranspiration (ET) for the Arctic drainage (estimated as a residual from $P$ and $P$-ET) based on data from 1960 through $1989(\mathrm{~mm})$. Plots are shown for alternate months.

[24] For all four basins, precipitation is lowest in February and March and highest during July. $P-$ ET tends to peak during autumn. These autumn maxima arise from the combined effects of a stronger vapor flux convergence and a strong seasonal decrease in precipitable water (i.e., a decrease in water vapor storage). The general inverse relationship between the seasonal cycles in $P$ and $P$-ET evident in Figures 3 and 4 is best expressed in the $\mathrm{Ob}$ (the westernmost basin). Here, mean $P$-ET for June and July is about $-10 \mathrm{~mm}$. Mean July $P-\mathrm{ET}$ is close to zero for the 

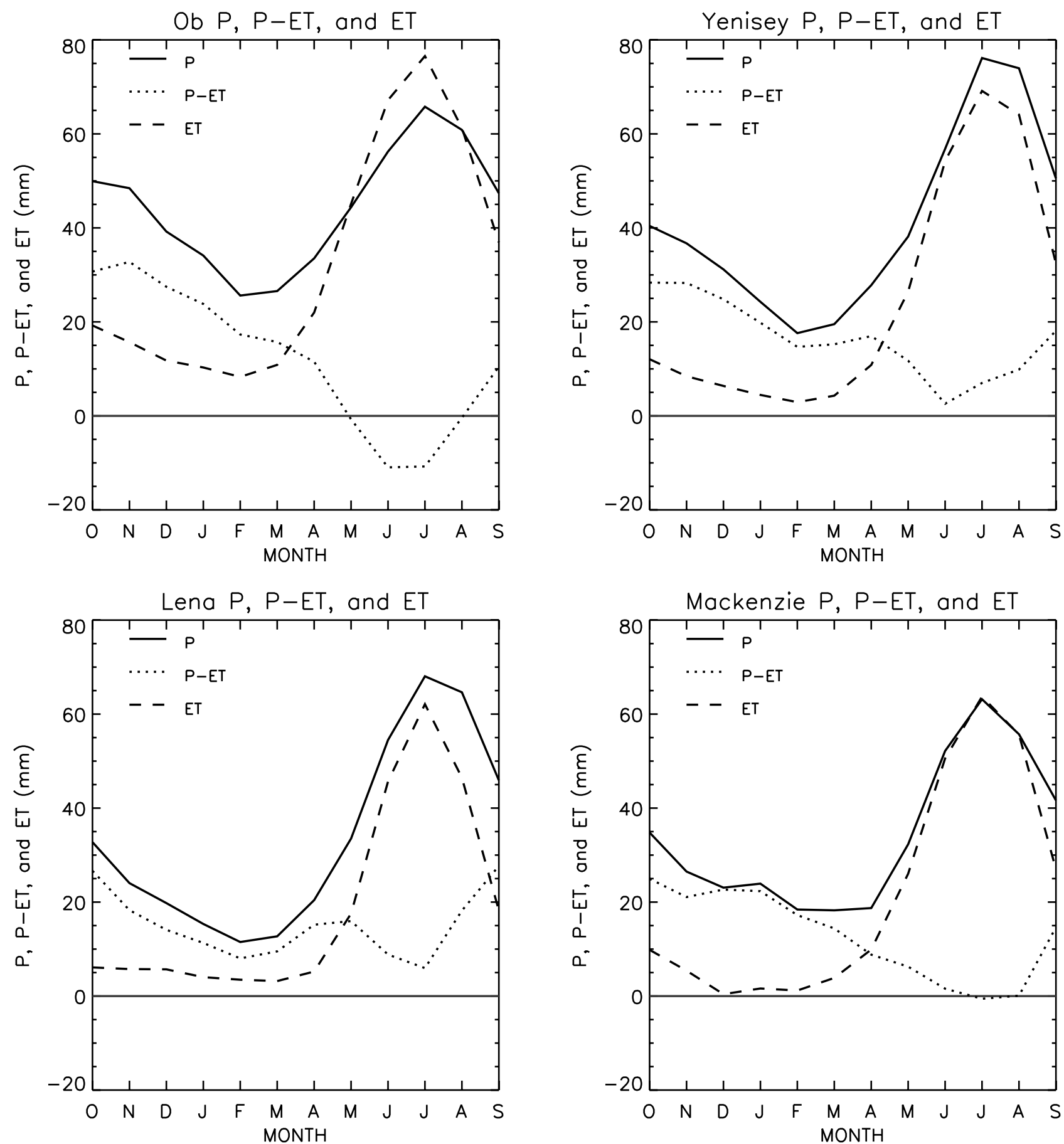

Figure 6. Mean monthly precipitatition $(P)$, precipitation minus evapotranspiration $(P-\mathrm{ET})$ and evapotranspiration (ET) for the four major watersheds, based on data from 1960 through 1989 (mm). ET is calculated as a residual from $P$ and $P-\mathrm{ET}$. Data are organized by the water year.

Mackenzie. Walsh et al. [1994] obtained qualitatively similar results for the Mackenzie using fluxes calculated from interpolated rawinsonde data. The July maxima in ET are between $60-75 \mathrm{~mm}$, highest for the $\mathrm{Ob}$. The $\mathrm{Ob}$ also has the highest winter ET rates.

[25] Table 1 lists mean values of $P, P-$ ET, ET and $R$ along with estimates of the runoff ratio $(R / P)$ and the fraction of precipitation lost through ET $(\mathrm{ET} / P)$. Values are based on the water year. Runoff $(R)$ is water-year discharge divided by the catchment area. Two estimates of ET are listed. The first is the difference between $P$ and $P$-ET (as in Figures 5 and 6). The second estimate (in parentheses) is the difference between $P$ and $R$. This second estimate of ET is in turn used to compute a second estimate of ET/P (also in parentheses). Means for the Eurasian basins are based on the water years $1960 / 1961$ through 1997/1998 ( $\mathrm{N}=39)$. For the Mackenzie, the shorter time series of precipitation and of 
Table 1. Components of the Water Budget Averaged for Water Years (1 October Through 30 September) for the Four Major Drainage Basins

\begin{tabular}{lcccccrr}
\hline & $P, \mathrm{~mm}$ & $P-\mathrm{ET}, \mathrm{mm}$ & $\mathrm{ET}, \mathrm{mm}$ & $R, \mathrm{~mm}$ & $R / P$ & $\mathrm{ET} / P$ & $N$ \\
\hline Ob & 533 & 150 & $383(396)$ & 138 & 0.26 & $0.72(0.74)$ & 39 \\
Yenisey & 495 & 189 & $306(256)$ & 239 & 0.48 & $0.62(0.52)$ & 39 \\
Lena & 403 & 179 & $224(182)$ & 221 & 0.55 & $0.56(0.45)$ & 39 \\
Mackenzie & 411 & 142 & $269(241)$ & 171 & 0.41 & $0.65(0.59)$ & 17 \\
\hline
\end{tabular}

discharge (at Red River) results in only 17 years with shared records.

[26] With perfect data sets and no additional sources or sinks of moisture, long-term means of computed $P$-ET and $R$ should be equal. The two terms agree within $9 \%$ for the $\mathrm{Ob}$, where $P$-ET exceeds runoff by $13 \mathrm{~mm}$. By contrast, for the Yenisey, Lena and Mackenzie, there is an apparent excess runoff (or $P$-ET deficit) of $50 \mathrm{~mm}(21 \%), 42 \mathrm{~mm}$ $(19 \%)$ and $29 \mathrm{~mm}(17 \%)$, respectively. Given that $R$ and $P$-ET are calculated from completely independent data sets, we are not displeased with these results. The imbalances could be due to a variety of errors. First, the Lena, Yenisey and Mackenzie are characterized by complex topography. This may introduce biases in $P$-ET associated with the smoothed topography in the NCEP model. Second, the $P$-ET data on the EASE grid are interpolated from a fairly coarse grid, which may not sufficiently capture variability across the drainage basins. Third, although specific humidity fields in the NCEP reanalysis are strongly constrained by observed data, they might also be influenced by the excessive summer ET rates in the model noted by Serreze and Hurst [2000]. With reference to the negative winter ET values in Figure 5, we argued that bias adjustments notwithstanding, $P$ may be too low in comparison to $P$-ET. However, the results in Table 1 lead us to conclude that if $P$-ET should be higher, $P$ must be underestimated to an even greater degree. Somewhat better closure might be obtained using mass balance corrections described by Alestalo [1983], and will be addressed in a future effort. Such corrections do not significantly alter temporal variability in computed $P$-ET [Rogers et al., 2001].

[27] According to Lammers et al. [2001], typical errors for measured discharge range from $\pm 2-5 \%$ for rivers without floodplains and $\pm 5-12 \%$ for those with floodplains. With low temperatures, estimates are less certain due to anchor ice, frazil ice and backwater conditions. It is reasonable to assume, however, that these errors are largely random. There are no large permanent glacier masses in these basins that could contribute additional runoff.

[28] Bowling et al. [2000] summarize various measurements of $R / P$ for the major Arctic-flowing rivers. Values for the $\mathrm{Ob}$ range from 0.25 to 0.33 . These are considerably lower than those for the Yenisey (0.47 to 0.54$)$ and Lena (0.46 to 0.61$)$. Existing estimates for the Mackenzie are intermediate $(0.30$ to 0.46$)$. The ranges for each watershed are presumed to reflect the use of different precipitation data sets. Our values are in accord with previous estimates. The basins can be similarly contrasted in terms of ET/P. Wateryear precipitation in the $\mathrm{Ob}$ is comparable to that for the Yenisey but is about $20 \%$ higher than for the Lena and Mackenzie. However, on the basis of both ET estimates in Table 1, a greater fraction of the precipitation in the $\mathrm{Ob}$ is lost through ET. The contrast in ET/P between the $\mathrm{Ob}$ and the other two Eurasian basins is more pronounced when the ratio is computed from basin ET using the difference between $P$ and $R$.

[29] The contrast between the $\mathrm{Ob}$ and the other basins in terms of $R / P$ and $\mathrm{ET} / P$ can be understood from regional differences in climatological surface air temperature, land cover and permafrost extent. Fields of mean January and July surface air temperature [Willmott and Robeson, 1995], the annual mean number of snow-free days (estimated from the weekly NOAA snow charts) and the percent of the surface represented by wetlands (based on the USGS Global Land Cover Characterization database) are provided in Figure 7. Table 2 lists basin averages. There is a clear progression from relatively mild January temperatures in the $\mathrm{Ob}\left(-18.7^{\circ} \mathrm{C}\right)$ to very cold conditions in the Lena $\left(-35.0^{\circ} \mathrm{C}\right)$. Comparatively low temperatures also characterize the Mackenzie basin. These differences are in accord with the higher winter ET rates in the Ob (Figure 6). The July temperature pattern is more zonal, but still with the highest temperatures over the $\mathrm{Ob}\left(18.1^{\circ} \mathrm{C}\right)$, fostering stronger summer ET in this basin. The number of snow-free days is also much greater in the $\mathrm{Ob}$, pointing to earlier and more prolonged warming of the soil. This will also contribute to high ET rates. Furthermore, in comparison to the other Eurasian basins, a larger part of the $\mathrm{Ob}$ is characterized as wetlands. ET over these areas is not limited by available soil moisture and will tend to occur at or near its potential rate. Over $6 \%$ of the Mackenzie is also characterized as wetlands. Note also from Figure 7 the large wetlands area east of the Lena. The net effect of higher ET in the $\mathrm{Ob}$ will be to reduce $R / P$ and increase $\mathrm{ET} / P$ relative to the other basins.

[30] The differences in runoff ratios are also related to permafrost. Permafrost acts as an impermeable barrier, such that precipitation and snowmelt are rapidly channeled into streams and rivers. Permafrost will also restrict plant growth through the growing season and limit root depth, reducing water losses through ET. The effect is to increase $R / P$. Table 3 summarizes permafrost distributions in the four basins, based on the IPA map. Permafrost for each EASE grid is classified as continuous, discontinuous, sporadic or isolated. The classifications are based on the fraction of the area underlain by permafrost (e.g., $>90 \%$ for continuous permafrost and $10-50 \%$ for sporadic permafrost). Table 3 shows the areas of each watershed represented by each classification, as well as the permafrost-free area. The two columns on the right estimate the range of actual area underlain by permafrost. The low end of the range assumes the minimum areal coverage from the classifications at each EASE grid (e.g., considering all discontinuous permafrost areas as $50 \%$ permafrost) while the high end of the range assumes maximum areal coverage (e.g,, considering all 

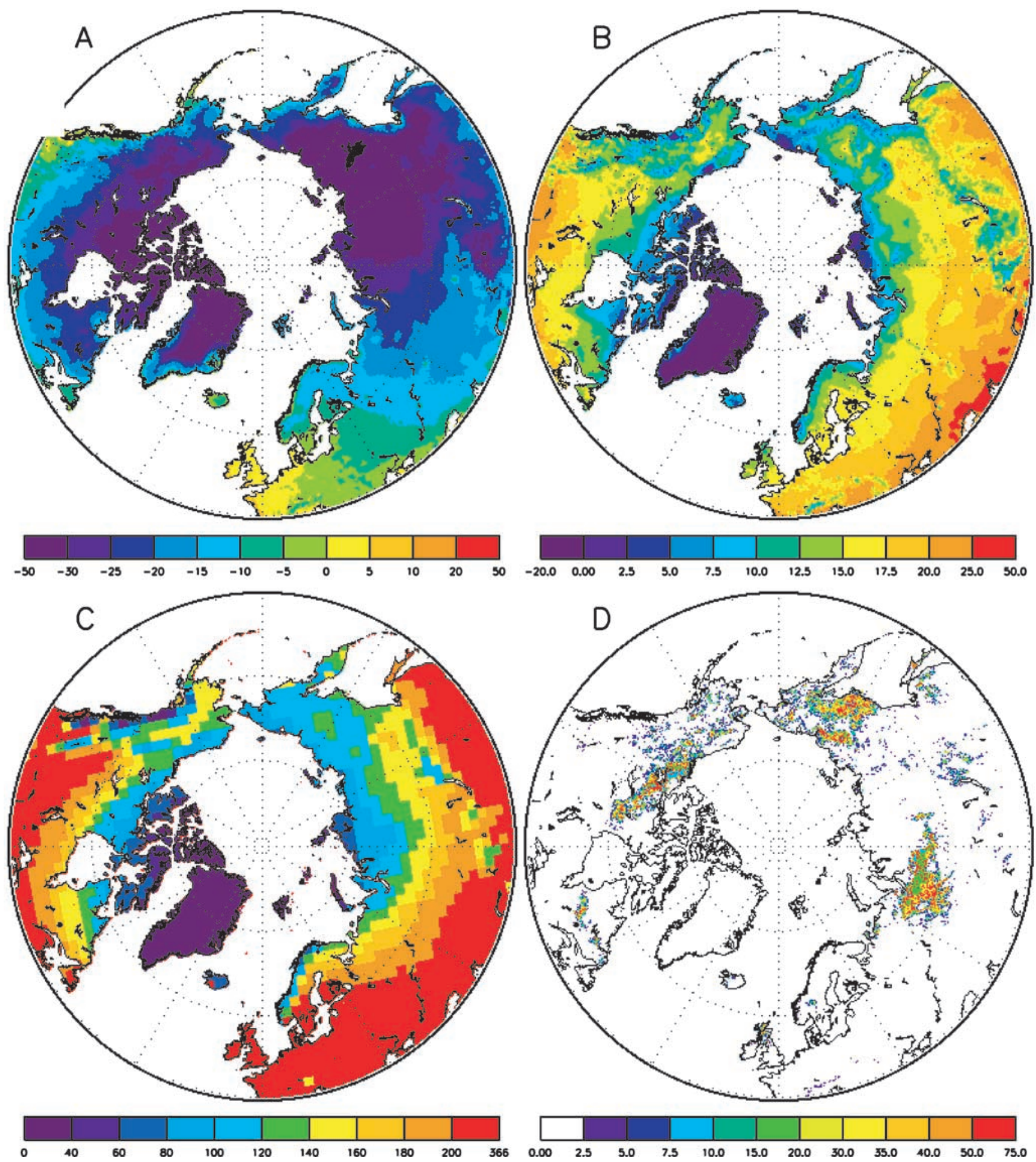

Figure 7. Fields of (a) mean January temperature $\left({ }^{\circ} \mathrm{C}\right)$, (b) mean July temperature $\left({ }^{\circ} \mathrm{C}\right)$, (c) the mean number of days over the year for which the surface is snow-free and (d) the fraction of the surface covered by wetlands $(\%)$.

discontinuous permafrost areas as $90 \%$ permafrost) [see Zhang et al., 2001].

[31] From Table 1, the largest contrast in $R / P$ is between the $\mathrm{Ob}$ and Lena. Only $4-10 \%$ of the $\mathrm{Ob}$ is underlain by permafrost (contributing to low $R / P$ ), compared to $78-93 \%$ of the Lena, mostly represented by continuous permafrost (contributing to high $R / P$ ). The extent of permafrost cover in the Yenisey and Mackenzie lies between that for the $\mathrm{Ob}$ and 
Table 2. Mean Temperature for January and July, Mean Number of Snow-Free Days, and Percent of Wetlands Cover for the Four Major Drainage Basins

\begin{tabular}{lrrrr}
\hline & January $T,{ }^{\circ} \mathrm{C}$ & July $T,{ }^{\circ} \mathrm{C}$ & Snow-Free Days & Wetlands Cover, $\%$ \\
\hline $\mathrm{Ob}$ & -18.7 & 18.1 & 186 & 6.6 \\
Yenisey & -26.5 & 15.2 & 163 & 3.7 \\
Lena & -35.0 & 14.7 & 144 & 0.8 \\
Mackenzie & -25.0 & 13.8 & 167 & 6.5 \\
\hline
\end{tabular}

Lena. In turn, these two basins have intermediate runoff ratios.

[32] We can put these results together to understand the mean water-year hydrographs for the four basins (based on the available period of record), expressed in terms of runoff (Figure 8). Each hydrograph shows the obvious effects of snowpack storage. Throughout the cold months, precipitation is stored in the snowpack. Runoff peaks during June for all watersheds. The peaks are much sharper in the Yenisey and Lena as compared to the $\mathrm{Ob}$. In part, this manifests lower mean temperatures in these basins from autumn through spring, meaning a longer period of snow accumulation and delayed spring melt. Once it becomes warm enough in June, the rapid melt of the snowpack appears as sharp runoff peaks. Especially for the Lena, the large extent of continuous permafrost fosters rapid movement of meltwater to streams, further contributing to the sharp runoff peak. By contrast, especially for the $\mathrm{Ob}$, a large proportion of precipitation and snowmelt is lost through ET, especially in summer, and is not available for runoff. Other effects not considered here include snowmelt storage in lakes and wetlands that can subdue peak discharge. This is believed to be pronounced for North American rivers such as the Mackenzie [Bowling et al., 2000].

\subsection{Precipitation Recycling}

[33] The amount of precipitation falling on a region can be divided into: 1) precipitation associated with water vapor transported into the region (advected precipitation); 2) precipitation associated with water that evaporates from the surface of the region and falls within the same region (locally derived precipitation). The precipitation recycling ratio is defined as $P_{\mathrm{m}} / P$, where $P_{\mathrm{m}}$ is the precipitation of local origin and $P$ is the total precipitation. The recycling ratio can be thought of as providing a sense of the importance of land-surface processes on the hydrologic budget. The topic has a long history, starting with Budyko and associates in the 1950s. Recent studies include Brubaker et al. [1993], Eltahir and Bras [1994, 1996] and Trenberth [1998]. Estimates of the recycling ratio are contingent on the size of the region considered. The ratio is smaller for areas of limited extent and increases for larger regions [Brubaker et al., 1993]. Obviously, all precipitation is recycled at the global scale.

[34] We consider monthly mean recycling ratios for four areas of identical area and shape. The four regions are bounded by $50^{\circ} \mathrm{N}$ and $70^{\circ} \mathrm{N}$ latitude and each span $25^{\circ}$ longitude bands from $60-85^{\circ} \mathrm{E}$ (west-central Eurasia), 85$110^{\circ} \mathrm{E}$ (central Eurasia), $110-135^{\circ} \mathrm{E}$ (east central Eurasia) and $110-135^{\circ} \mathrm{W}$ (western North America). The area of each region is $3.08 \times 10^{6} \mathrm{~km}^{2}$. These regions are chosen to roughly represent the $\mathrm{Ob}$, Yenisey, Lena and Mackenzie basins (see Figure 1). We choose equal areas (rather than areas defined by the true basin boundaries) to allow for direct comparisons. The western North American domain (Mackenzie) does include some ocean areas as well as coastal regions where precipitation is very high. Results are based on the period 1960-1999 for the Eurasian domains and 1960-1989 for the western North American domain.

[35] A number of different formulations of the recycling ratio can be found. Following Trenberth [1998], we employ the approach of Brubaker et al. [1993]. This is given as

$$
\frac{P_{m}}{P}=\frac{1}{\left(1+\frac{2 * F^{+}}{\mathrm{ET} * A}\right)}
$$

where A is the area of the region and ET is evapotranspiration averaged over the region. For ET, we used the climatological monthly means for each region based on the difference between $P$ and computed $P$-ET. $\mathrm{F}+$ is the advective moisture term. It is calculated as the line integral of the component of the vertically integrated moisture flux directed into the region. It should not be confused with the vapor flux convergence, which is the difference between $\mathrm{F}+$ and the component of the moisture flux directed out of the domain $(\mathrm{F}-)$. Calculation of $\mathrm{F}+$ uses the monthly mean vertically integrated moisture fluxes at the $2.5 \times 2.5$ degree grid available from NCEP. The formulation assumes equilibrium conditions and a well-mixed atmosphere. This means no changes in atmospheric moisture content and that

Table 3. Permafrost Area $\left(10^{6} \mathrm{~km}^{2}\right)$ for the Four Major Drainage Basins

\begin{tabular}{|c|c|c|c|c|c|c|c|}
\hline \multirow[b]{2}{*}{ Permafrost Regions } & \multirow{2}{*}{$\begin{array}{c}\text { Continuous } \\
(>90 \%)^{\mathrm{a}}\end{array}$} & \multirow{2}{*}{$\begin{array}{c}\text { Discontinuous } \\
(50-90 \%)^{\mathrm{a}}\end{array}$} & \multirow{2}{*}{$\begin{array}{c}\text { Sporadic } \\
(10-50 \%)^{\mathrm{a}}\end{array}$} & \multirow{2}{*}{$\begin{array}{l}\text { Isolated } \\
(<10 \%)^{\mathrm{a}}\end{array}$} & \multirow{2}{*}{$\begin{array}{c}\text { Nonpermafrost } \\
\text { Areas }(0 \%)^{\mathrm{a}}\end{array}$} & \multicolumn{2}{|c|}{ Total Area Underlain by Permafrost } \\
\hline & & & & & & Areas & Fraction $(\%)^{\mathrm{b}}$ \\
\hline \multicolumn{8}{|l|}{ River Basins (Area) } \\
\hline $\mathrm{Ob}(3.022)^{\mathrm{c}}$ & 0.042 & 0.111 & 0.270 & 0.337 & 2.188 & $0.120-0.311$ & $4-10$ \\
\hline Yenisei $(2.576)^{\mathrm{c}}$ & 0.816 & 0.300 & 0.506 & 0.664 & 0.226 & $0.935-1.405$ & $36-55$ \\
\hline Lena $(2.443)^{\mathrm{c}}$ & 1.939 & 0.268 & 0.161 & 0.074 & 0.001 & $1.895-2.268$ & $78-93$ \\
\hline Mackenzie $(1.693)^{\mathrm{c}}$ & 0.276 & 0.512 & 0.447 & 0.154 & 0.239 & $0.549-0.977$ & $32-58$ \\
\hline
\end{tabular}

${ }^{\text {a }}$ Percentage of area underlain by permafrost.

${ }^{\mathrm{b}}$ Total area underlain by permafrost in each river basin divided by the total area of the basin.

${ }^{\mathrm{c}}$ Total area of each river basin 

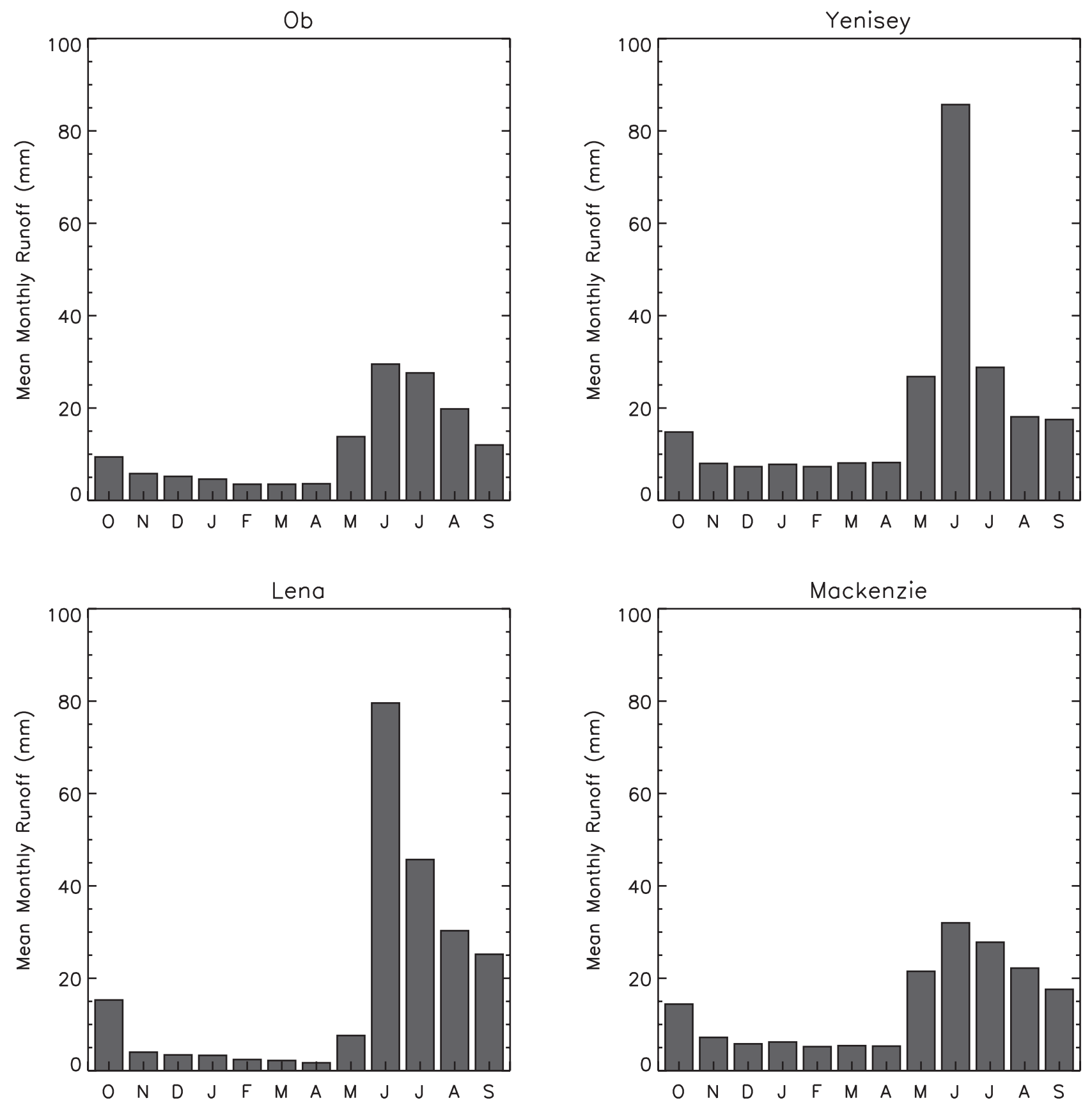

Figure 8. Mean monthly hydrographs organized by water year for the four major watersheds, expressed as runoff $(\mathrm{mm})$.

the ratio of advected to locally derived precipitation is equal to the ratio of average advected to evaporated moisture in the air. A large recycling to advection ratio will result when the moisture advection term $\mathrm{F}+$ is small in comparison with ET.

[36] Mean seasonal cycles of the calculated recycling ratio are provided in Figure 9. For the Eurasian domains, the ratio is largest during July. This is primarily due to the peak in ET as the term F+ still tends to be fairly large in summer. By contrast, the peak for the western North American (Mackenzie) domain is one month earlier in June. Peak values range from 0.22 (East Central Eurasia, or Lena) to 0.28 (central Eurasia, or Yenisey). Winter values range from 0.0 to 0.11 , largest for western North America. This points to a significant effect of the land surface on the summer hydrologic regime.

\section{Variability and Trends}

\subsection{Seasonal $P$-ET and the Regional Circulation}

[37] Relationships are first examined between extremes of computed $P$-ET for winter and summer and the circulation of the middle-troposphere $(500 \mathrm{hPa})$ and at sea level (SLP) We focus on $P$-ET as (a) it represents effective moisture (b) 40-year (1960-1999) records are available for each watershed. A composite approach is employed. For each month 
$\mathrm{Ob}$
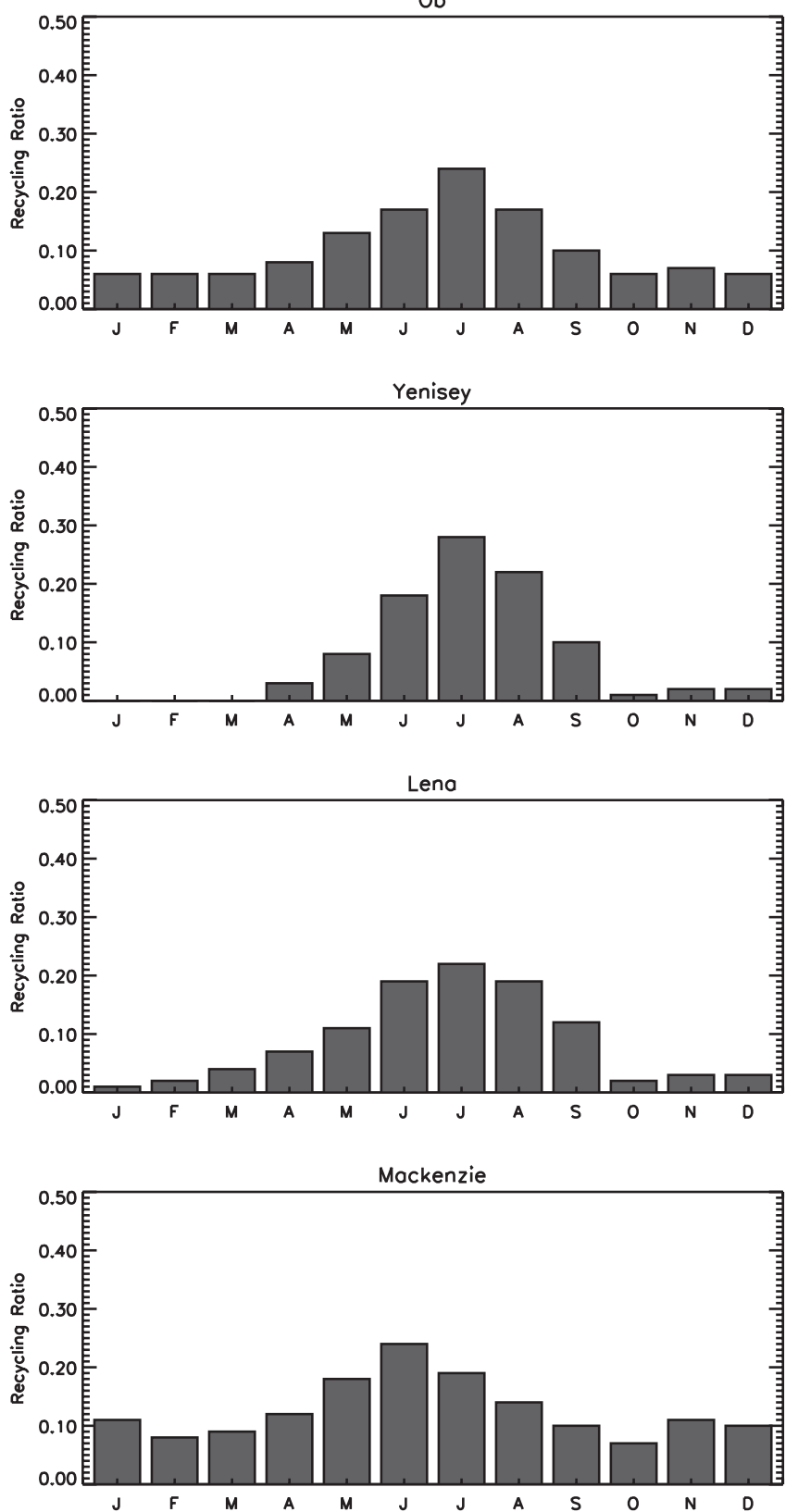

Figure 9. Mean monthly precipitation recycling ratio $\left(P_{\mathrm{m}} / P\right)$ for four domains chosen to roughly represent the $\mathrm{Ob}$, Yenisey, Lena and Mackenzie basins. Each region is identically shaped spanning 20 degrees of latitude from $50-70^{\circ} \mathrm{N}$ and 25 degrees of longitude and representing an area of $3.08 \times 10^{6} \mathrm{~km}^{2}$ (see Figure 1).

in the 40-year records, we identified for each of the four watersheds the ten years with the highest $P-\mathrm{ET}$ and the ten years with the lowest $P-\mathrm{ET}$. These represent the top and bottom $25 \%$ (quartile) of cases, respectively. Mean $500 \mathrm{hPa}$ and SLP fields from the NCEP reanalysis were compiled for winter (JFM) and summer (JJA) based on the high and low composite members in each month. Each seasonal composite contains 30 cases, ten from each month. This mitigates the potential influence on the composite means of one or several outlying composite members. Climatological mean fields of $500 \mathrm{hPa}$ height and SLP are provided in Figure 10. Figures 11-14 display the composite difference fields (high $P$-ET composite mean minus the low $P$-ET composite). The use of composite differences assumes that the high and low composites depict opposing circulation anomalies and that the opposing anomalies have similar magnitude. In general, our results justify this assumption. There are some nonlinearities which are discussed as needed.

[38] Variability in $P$-ET for the $\mathrm{Ob}$ basin (Figure 11) is related to the Urals trough. For long term winter means (Figure 10), the Urals trough is a weak feature in the primarily zonal flow over west-central Eurasia. The mean trough axis is located at approximately $30^{\circ} \mathrm{E}$ at $40^{\circ} \mathrm{N}$, tilting eastward at higher latitudes to about $60^{\circ} \mathrm{E}$ at $60^{\circ} \mathrm{N}$. The composite differences in $500 \mathrm{hPa}$ geopotential height (SLP) over the $\mathrm{Ob}$ basin peak at about $150 \mathrm{~m}(12 \mathrm{hPa})$, near the mean longitude of the $500 \mathrm{hPa}$ Urals trough. The high and low composite fields (not shown) reveal that high $P-\mathrm{ET}$ in winter is favored when the trough is deeper than normal, but also shifted slightly east of its climatological position. By contrast, for winters with low $P-\mathrm{ET}$, the trough axis is shifted about 10 degrees west of its climatological position. Our interpretation is that the deeper and eastward shifted Urals trough favors cyclonic vorticity advection, moisture convergence and precipitation over the $\mathrm{Ob}$, while the westward-shifted trough has opposing effects. Qualitatively similar relationships are observed for summer. For longterm means, the Urals trough during summer is located at about $80^{\circ} \mathrm{E}$ (Figure 10). While the general circulation in summer is weaker, the Urals trough is better expressed than its winter counterpart. Summers with high $P$-ET tend to occur when the trough is near or slightly west of its climatological position and deeper than normal. Summers with low $P$-ET occur with positive height anomalies in the same area, associated with a shift of the trough slightly east of its usual position. Maximum composite differences, however, are a modest $60 \mathrm{~m}$, associated with a local difference in SLP of $3 \mathrm{hPa}$.

[39] Turning to the Yenisey, the obvious feature at 500 $\mathrm{hPa}$ during winter is a north-south pattern of opposing differences (Figure 12). Winters with high $P-\mathrm{ET}$ are found with negative height anomalies over the Eurasian side of the Arctic Ocean, largest $(30 \mathrm{~m})$ near the coast between about $100-120^{\circ} \mathrm{E}$. Positive anomalies of similar magnitude lie over west-central Eurasia. Opposing anomalies but of somewhat larger magnitude emerge for the low composite. This yields composite differences at the two anomaly centers of about $\pm 80 \mathrm{~m}$. This is associated with a change in the strength of the zonal flow over the watershed, with stronger flow for high $P$-ET. For SLP, there is a maximum composite difference of about $-8 \mathrm{hPa}$ centered just south and west of the Taymyr Peninsula, ahead of the highcomposite trough axis. The summer composite differences are like those for the $\mathrm{Ob}$ in depicting a control by the Urals trough. The high composite has the trough axis at about $90^{\circ} \mathrm{E}$, roughly 10 degrees east of the location associated with high $P$-ET in the $\mathrm{Ob}$. For the low composite, the regional $500 \mathrm{hPa}$ circulation is much more zonal-i.e., the Urals trough is weak. The maximum composite differences, however, are only $-50 \mathrm{~m}$, consistent with the modest signal in SLP. 


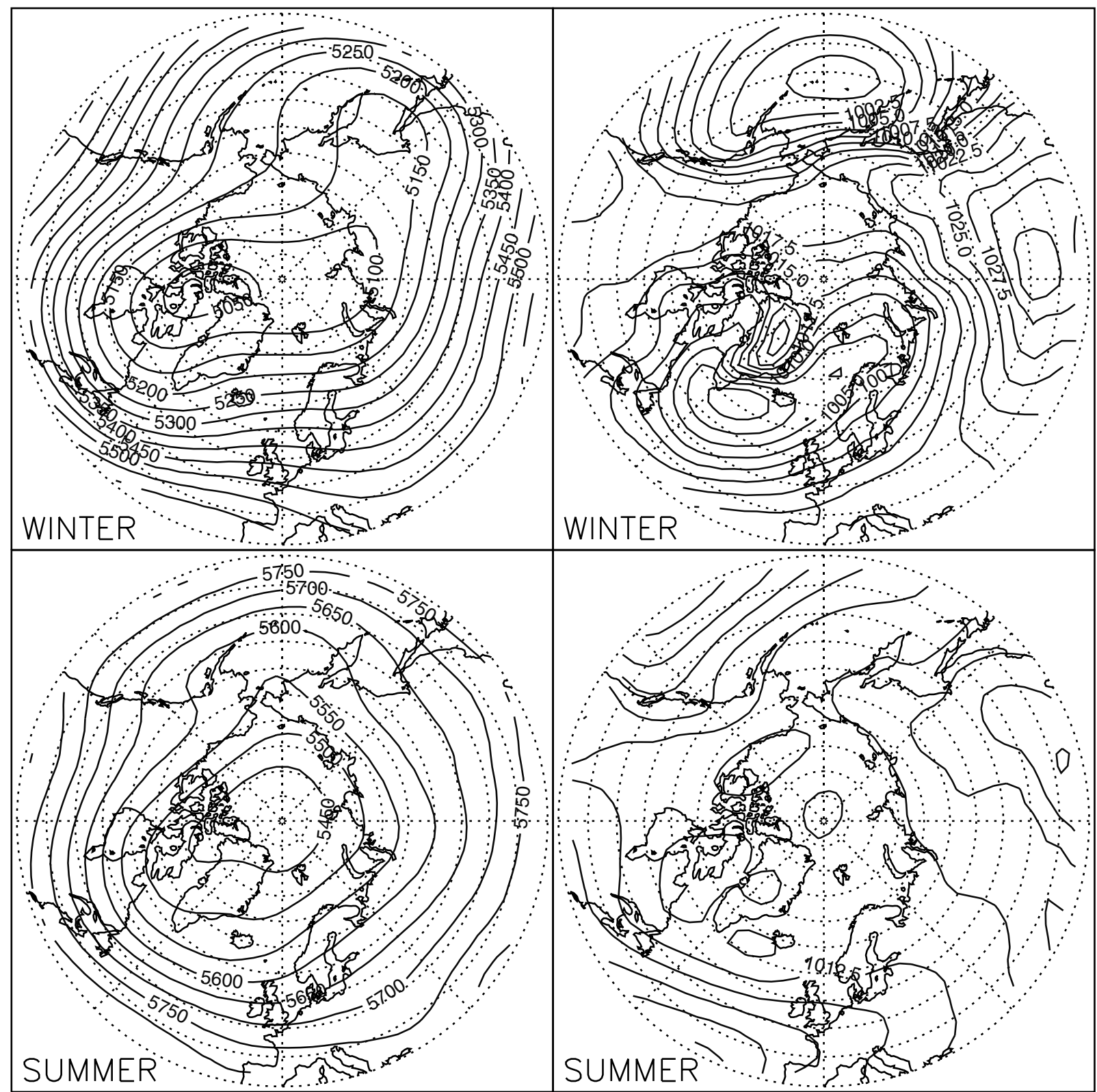

Figure 10. Fields of mean $500 \mathrm{hPa}$ height (left panels, in geopotential meters) and sea level pressure (right panels, in $\mathrm{hPa}$ ) for winter and summer, based on the period 1960-1999.

[40] Winter results for the Lena (Figure 13) share similar characteristics. There is a north-south pattern of opposing composite differences, but with the difference center over Eurasia shifted eastward. Again, this is associated with stronger zonal flow over the watershed for high $P$-ET. Maximum SLP differences over the Taymyr Peninsula are $10 \mathrm{hPa}$. Again, the summer results depict more of a Urals trough influence. High $P$-ET during summer tends to occur with the trough slightly east of its usual position. Low summer $P$-ET is associated with a weak $500 \mathrm{hPa}$ ridge over the basin.

[41] The Mackenzie basin lies under the descending leg of the climatological western North American ridge (Figure 10). Winters with high $P$-ET are favored by positive $500 \mathrm{hPa}$ anomalies over the north Pacific with above normal SLP, and negative anomalies over central Canada. An opposing pattern is evident for winters with low $P-$ ET (Figure 14). The anomalies associated with the high (low) composites reflect weakening (strengthening) of the $500 \mathrm{hPa}$ ridge over extreme western north America, increased (decreased) zonal flow and stronger (weaker) baroclinicity over the Mackenzie basin. Results for summer are quite different. The high composite shows stronger zonal flow in the southern part of the Mackenzie not apparent in the low composite. Our winter results are very similar to those of Bjornsson et al. [1995], who examined relationships between Mackenzie precipitation anomalies and $700 \mathrm{hPa}$ composite fields.

[42] For both winter and summer, the Mackenzie basin is a region of frequent lee-side cyclogenesis [Serreze et 


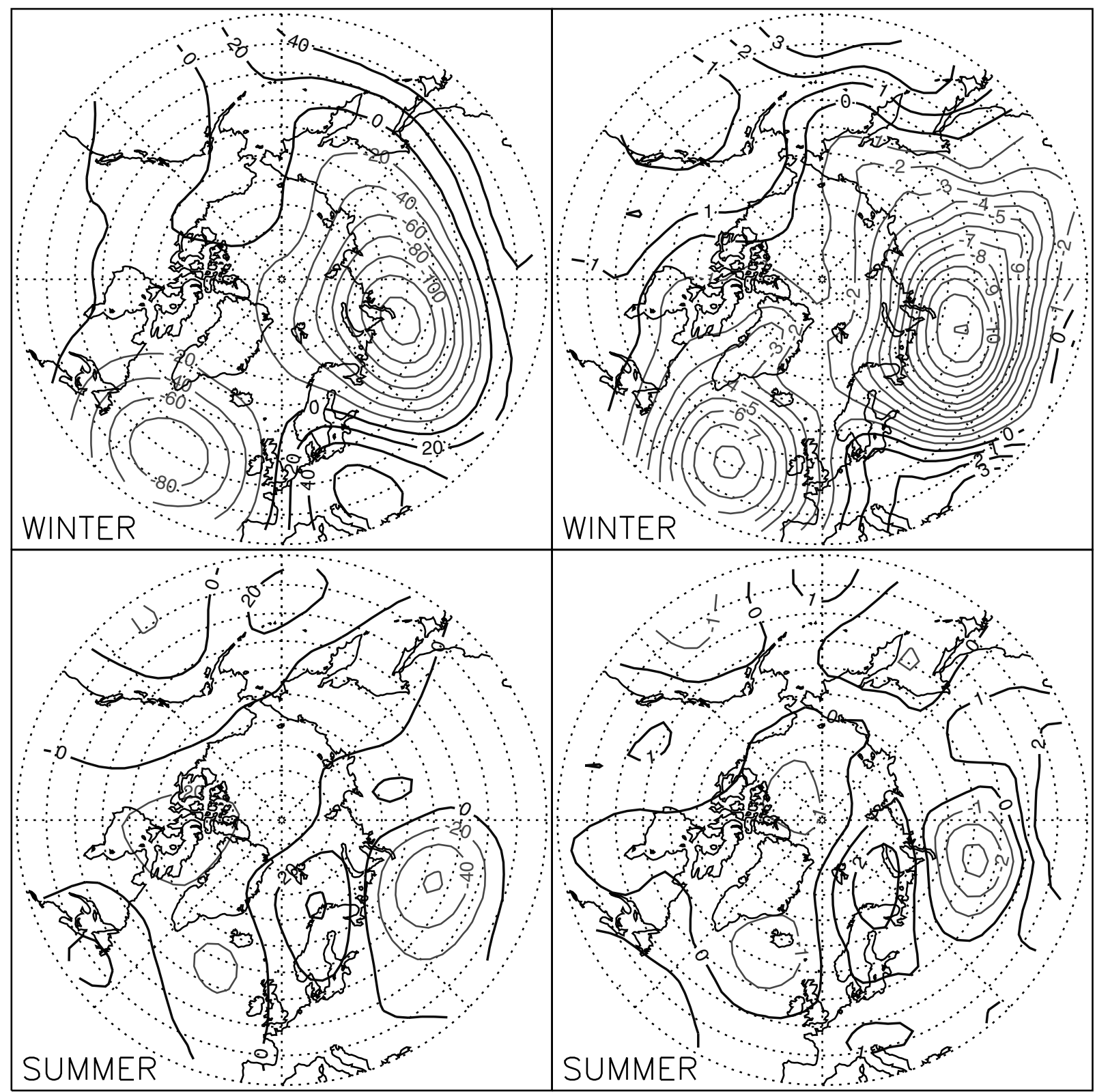

Figure 11. Composite analyses for the $\mathrm{Ob}$ of $500 \mathrm{hPa}$ circulation (left panels, in geopotential meters) and SLP (right panels, in $\mathrm{hPa}$ ) for winters and summers with high and low $P-\mathrm{ET}$. Displayed fields of are the high $P$-ET composite minus the low $P$-ET composite. Positive differences are indicated with bold contours while negative differences are indicated by light contours. Each composite contains 30 members.

al., 2001a; Lackmann and Gyakum, 1996; Misra et al., 2000]. Lackmann and Gyakum [1996] find that a particularly common situation associated with widespread precipitation events in the Mackenzie during autumn, winter and spring is lee cyclogenesis over the southern Mackenzie Basin in association with a strong cyclone over the Gulf of Alaska. They term these Gulf Redevelopment (GR) cases. A key requirement for high precipitation in GR events is a persistent influx of Pacific moisture. "Wet" GR events tend to occur when the 500 $\mathrm{hPa}$ North American ridge is centered over the southwestern United States with a trough centered over the Gulf of Alaska, resulting in strong southwesterly geo- strophic flow into the southern Mackenzie basin. "Dry" GR events are associated with substantially weaker southwesterly flow.

[43] In summary, for both winter and summer, variability in $P$-ET over the $\mathrm{Ob}$ is closely allied with the strength and location of the Urals trough. A Urals trough influence is also apparent in summer for the Yenisey and Lena. For winter, $P-$ ET variations in these latter basins are more closely associated with variability in the strength of the zonal flow. A key feature of high $P$-ET for both summer and winter in the Mackenzie is less-side cyclogenesis, associated with a stronger-than-average zonal flow and a persistent influx of Pacific moisture. 


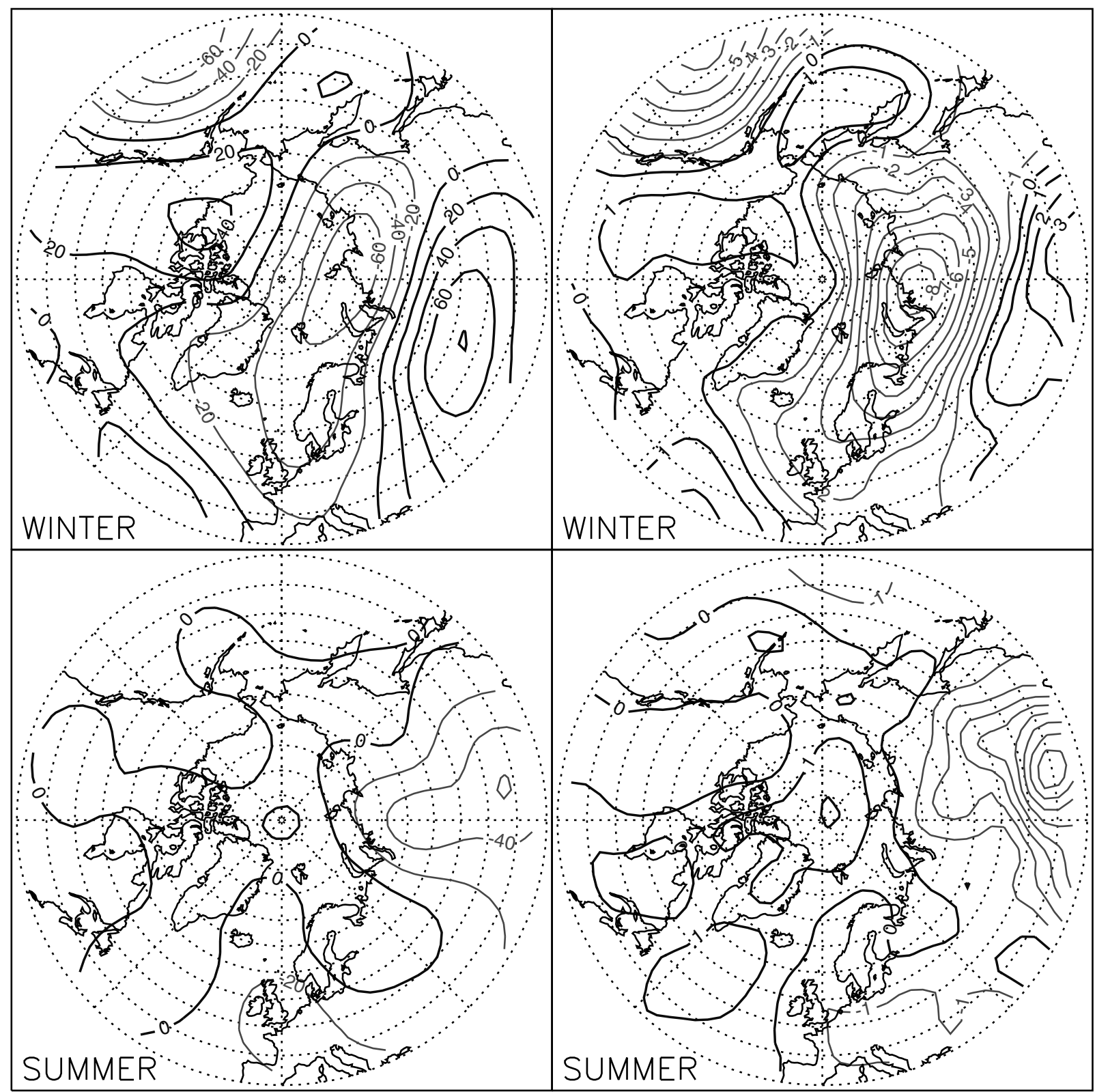

Figure 12. Composite analyses for the Yenisey of $500 \mathrm{hPa}$ circulation (left panels, in meters) and SLP (right panels, in $\mathrm{hPa}$ ) for winters and summers with high and low $P$-ET. Displayed are fields of the high $P$-ET composite minus low $P$-ET composite. Positive differences are indicated with bold contours while negative differences are indicated by light contours. Each composite contains 30 members.

[44] Circulation signals of the same sense but stronger than those examined here emerge when composites are constructed with the top and bottom $10 \%$ or $15 \%$ of cases. As expected on the basis of previous studies just described for the Mackenzie, similar conclusions are obtained when circulation composites are based on precipitation extremes. This is further supported in summaries of the squared correlations between monthly $P$ and $P$-ET for each basin (Figure 15). These are based on the available record lengths for the two variables within each basin $(\mathrm{N}=40$ for the Eurasian basins and $\mathrm{N}=30$ for the Mackenzie). In general, the squared correlations (depicting positive relationships between the two variables) exceed 0.40 and are often much higher.

\subsection{Relationships With Teleconnection Patterns}

[45] Squared correlations were computed between the monthly time series of $P$-ET in each of the four basins and the Arctic Oscillation (AO) index. The AO represents the leading mode of variability in Northern Hemisphere SLP as evaluated from Principal Component Analysis (PCA) [Thompson and Wallace, 1998, 2000]. The AO has a strong center of action over the central Arctic Ocean and weaker centers of opposing sign over the north Atlantic and 


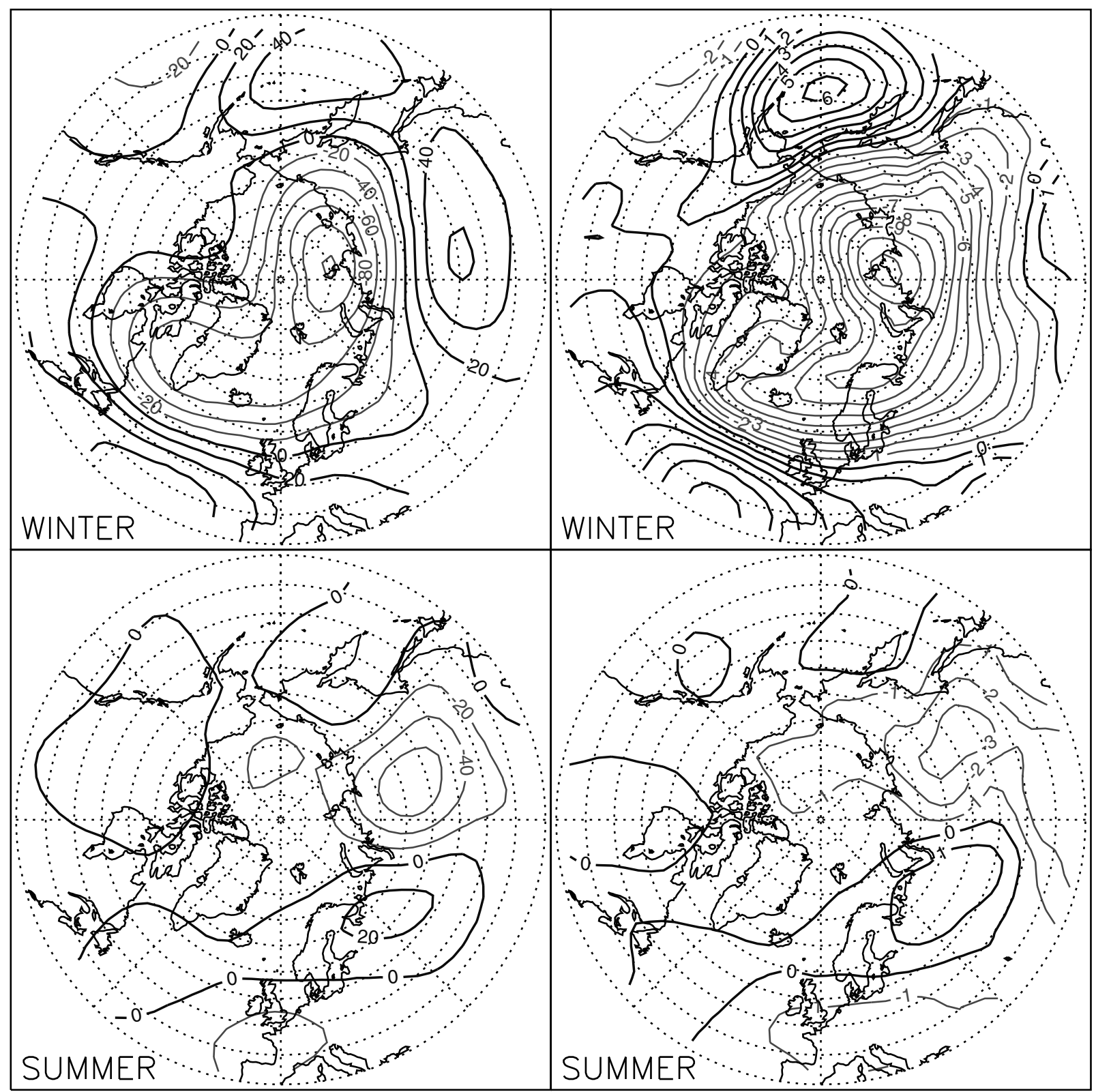

Figure 13. Composite analyses for the Lena of $500 \mathrm{hPa}$ circulation (left panels, in meters) and SLP (right panels, in $\mathrm{hPa}$ ) for winters and summers with high and low $P-\mathrm{ET}$. Displayed are fields of the high $P$-ET composite minus low $P$-ET composite. Positive differences are indicated with bold contours while negative differences are indicated by light contours. Each composite contains 30 members.

north Pacific basins. The structure of the AO strongly resembles that of the North Atlantic Oscillation (NAO) and the exact relationship between the two is still being debated. We also computed squared correlations between the $P$-ET time series and indices from a suite of different teleconnection patterns. These were obtained from the NOAA Climate Prediction Center (http://www.cpc.ncep. noaa.gov/data/teledoc/telecontents.html). The indices are based on rotated PCA. Index values for each teleconnection are only provided for months when the pattern appears as one of the leading (i.e., significant) rotated modes.

[46] Relationships between the AO and $P$-ET are weak for all months. None of the squared correlations exceed 0.17 . Findings are similar with respect to the NAO index.
Correlations are also low with the $\mathrm{AO}$ and NAO time series and a time series of $P$-ET for a Eurasian domain that combines the $\mathrm{Ob}$, Yenisey and Lena. The low correlations are not surprising given that the strongest circulation signals associated with the AO are found in the North Atlantic. Squared correlations computed between monthly $P$-ET in each watershed and other teleconnection indices provided by NOAA also reveal no remarkable relationships. For the East Atlantic (EA), EA-Jet, West Pacific (WP), East Pacific (EP), East Atlantic/Western Russia (EA/WR), Scandinavia (SCA), and Tropical Northern Hemisphere (TNH) patterns, one can find at least one month where for a given watershed there is a squared correlation exceeding 0.20 . However, there is little month-to-month persistence in significant 


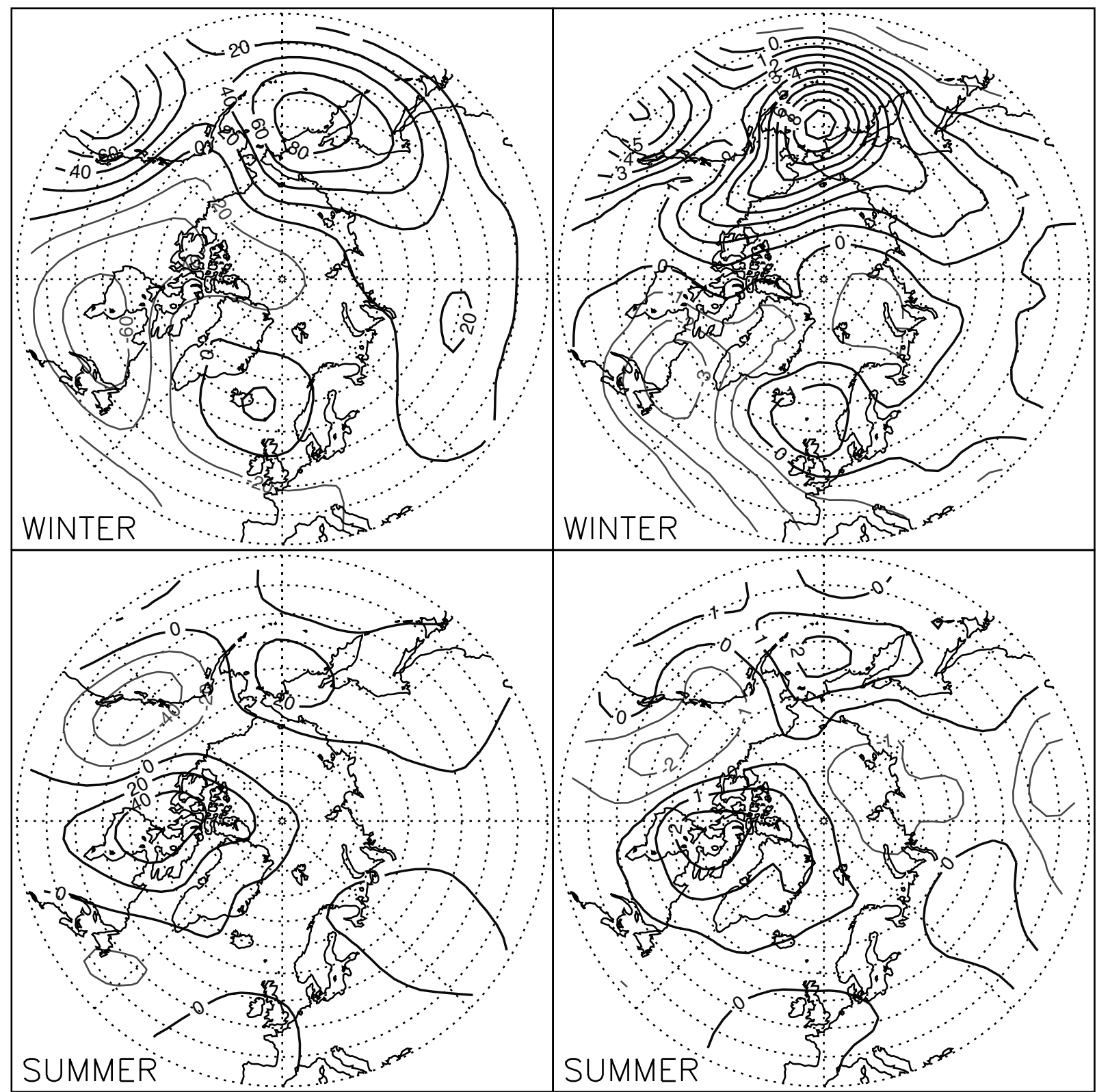

Figure 14. Composite analyses for the Mackenzie of $500 \mathrm{hPa}$ circulation (left panels, in meters) and SLP (right panels, in $\mathrm{hPa}$ ) for winters and summers with high and low $P$-ET. Displayed are fields of the high $P$-ET composite minus low $P$-ET composite. Positive differences are indicated with bold contours while negative differences are indicated by light contours. Each composite contains 30 members.

correlations. This points to variability in $P$-ET for each of the watersheds as responding to circulation changes that are more regional in nature.

\subsection{Time Series of Budget Components}

[47] We next examine water-year time series of $R, P-\mathrm{ET}$, ET and $P$ for each basin (Figure 16). The record lengths for each variable and basin depend on data availability. In accord with Figure 15, there is a fairly close correspondence between interannual variability in $P$ and $P-$ ET. Also clear from the difference in magnitudes of $P$ and $R$ are the higher runoff ratios in the Yenisey, Lena and Mackenzie as compared to the Ob. Except for the Lena, the underestimate of $P$-ET as compared to $R$ (see Table 1 ) is not systematic, with $P$-ET exceeding $R$ for some years. Also excepting the Lena, there is little relation between variations in $R$ and with either $P$ or $P$-ET. For the Ob, Yenisey, Lena and Mackenzie, the squared correlations between water-year time series of $R$ and $P$-ET are 0.04, 0.00, 0.52 and 0.22, respectively. Corresponding squared correlations between $R$ and $P$ are $0.03,0.08,0.61$ and 0.40 .

[48] The rather strong relationships between $R$ and both $P$ and $P$-ET in the Lena are consistent with the extensive permafrost in this basin. Approximately $80 \%$ of the Lena is underlain by continuous permafrost (Table 3), which promotes rapid movement of precipitation and snowmelt into river networks. With regard to the low correlations for the $\mathrm{Ob}$, Yenisey and Mackenzie, one must also acknowledge 

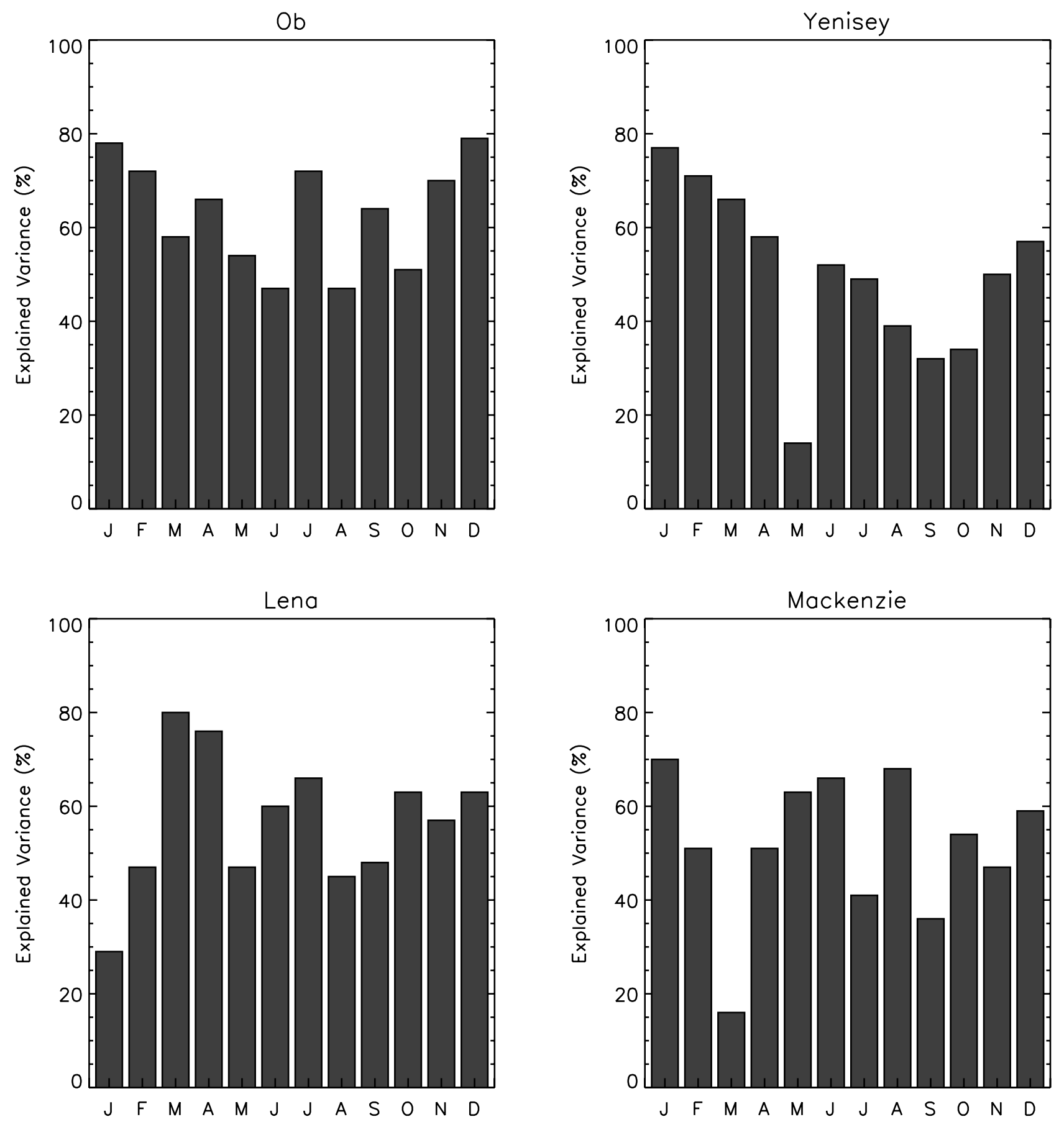

Figure 15. Squared correlation coefficients between monthly $P$ and $P-\mathrm{ET}$ for the four watersheds.

effects of measurement error. However, the good correspondence between $P$ and $P$-ET for all four basins argues that these two variables are correctly responding to the same environmental forcing. Errors in $R$ would also reduce the correlations. Effects of water diversions and impoundments are considered to be minor [Lammers et al., 2001], but are not well documented.

[49] We are reluctant to take trends computed from reanalysis variables at face value $(P-\mathrm{ET}$ and $\mathrm{ET})$. The reason is that the NCEP time series can be influenced by changes in the amount and quality of assimilation data [Kistler et al., 2001]. For example, inspection of the time series in Figure 16 for the $\mathrm{Ob}$ suggests a positive trend in water-year $P$-ET and a negative trend in ET. Over 19601999, the linear trends in these two variables (evaluated with a two-tailed t-test) are statistically significant at the $99 \%$ level. The total changes over 40 years are $+82 \mathrm{~mm}$ $(P-\mathrm{ET})$ and $-64 \mathrm{~mm}(\mathrm{ET})$. There is no significant trend in $P$, implying that the trend in $P-\mathrm{ET}$ is a response to decreased in ET. One would expect increased water-year runoff, but this is not observed. The regression line for $R$ is essentially flat. The NCEP trends are clearly suspect. An opposing set of significant water-year trends in $P-\mathrm{ET}$ and ET over the period 1960-1999 is calculated for the Yenisey 

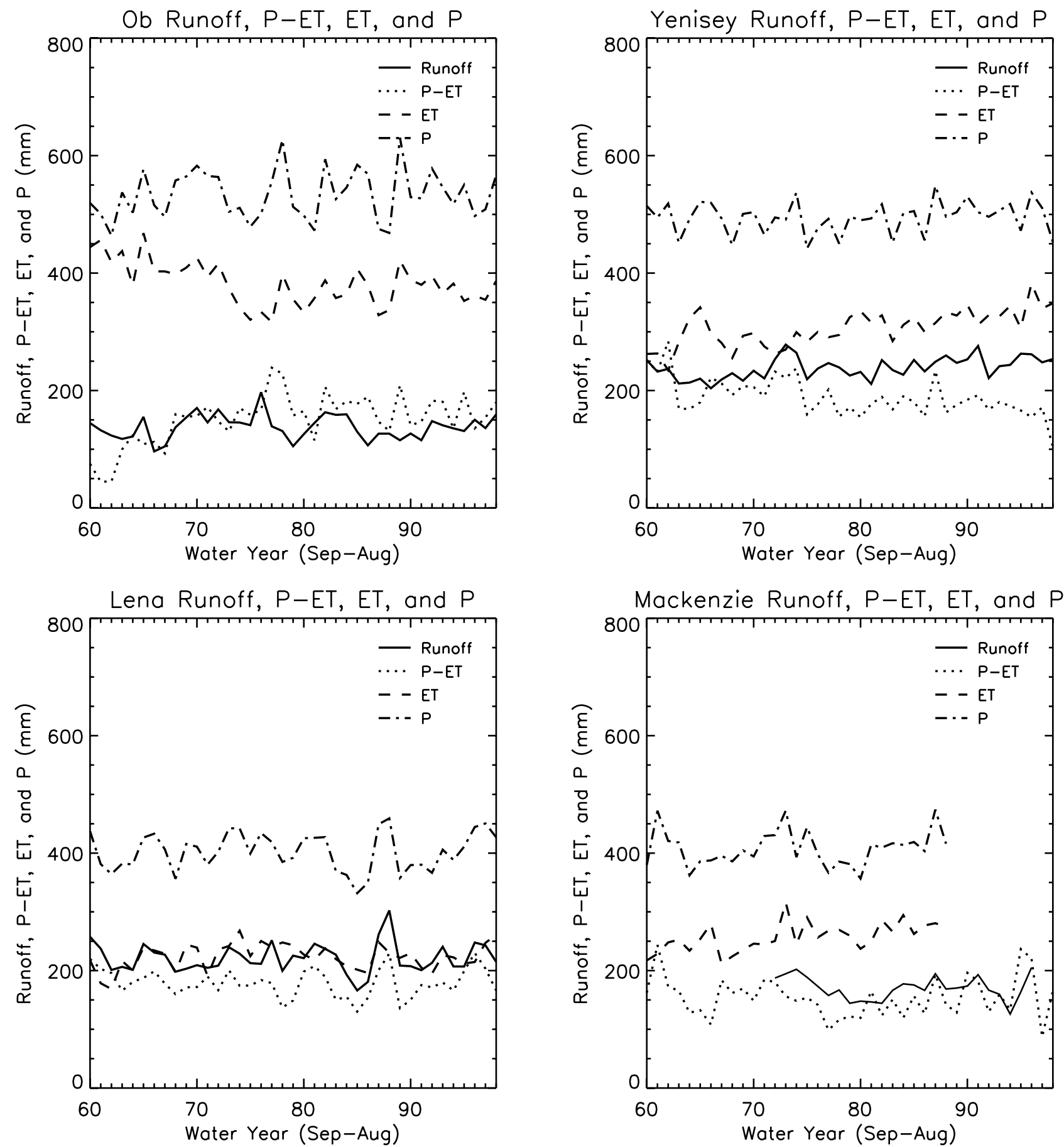

Figure 16. Water-year time series $(\mathrm{mm})$ of runoff $(R)$, precipitation $(P)$, precipitation minus evapotranspiration $(P-\mathrm{ET})$ and ET for the four watersheds. ET is calculated as a residual from $P$ and $P-$ ET.

(total changes of $-68 \mathrm{~mm}$ and $+78 \mathrm{~mm}$, respectively). While not obvious in Figure 16, these are accompanied by a small but significant increase in $R(30 \mathrm{~mm})$. Grabs et al. [2001] also show a positive trend in annual runoff for the Yenisey starting in 1966. As we would expect runoff to be decreasing, these results are also suspect. Neither of the other basins show any significant water-year trends.

[50] There is the related issue of time series sampling. Closer inspection of Figure 16 reveals that the suspect water-year trends in $P$-ET and ET for the $\mathrm{Ob}$ are strongly influenced by the earlier years of the record. When the analysis is restricted to 1970 onward, the trends are no longer significant. In fact, there is a barely significant (90\% confidence level) decrease in annual runoff. By contrast, the positive trend in water-year $R$ for the Yenisey computed with the shorter record is still significant, albeit only at the $90 \%$ level. The water-year trends in both $P-$ ET and ET are retained. 

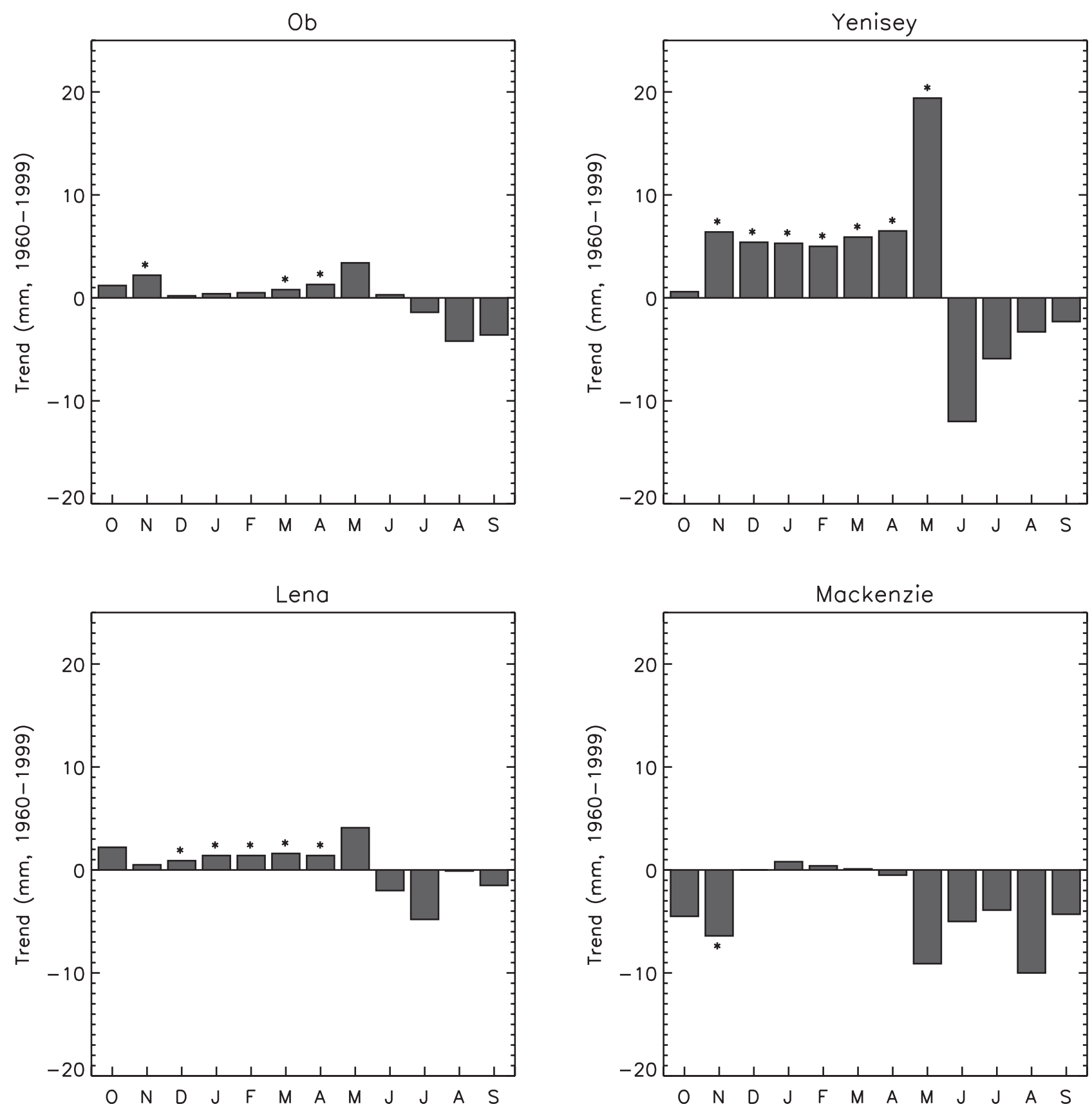

Figure 17. Linear trends in monthly runoff organized by water year for the four watersheds, expressed as total changes $(\mathrm{mm})$ over the period 1960-1999. Significant trends (at least the 95\% level) are indicated with asterisks.

[51] Figure 17 summarizes linear trends in monthly runoff as total changes (mm) over 1960-1999 based on the computed slopes. Records for the Mackenzie are only available for 1972-1997. The 40-year changes are shown for this basin to allow comparisons with the Eurasian watersheds. Significant trends (at least the 95\% level) are indicated by asterisks. Note first that the Eurasian basins exhibit significant increases in runoff for the cold months. The signals in the Yenisey are much more pronounced than those elsewhere. In the Yenisey there is also a very sharp increase in May runoff. As broken down by standard calendar seasons, there are significant increases in runoff for both winter $(+16 \mathrm{~mm})$ and spring $(+32 \mathrm{~mm})$ in the Yenisey and for winter in the Lena $(+4 \mathrm{~mm})$. The basic pattern of trends remains when looking at the shorter (1970-1999) period. Positive trends in winter runoff for the Eurasian rivers have already been noted in several studies [Grabs et al., 2000; Semiletov et al., 2000; Yang et al., 2002]. The general conclusion is that these relate to the winter and spring warming seen in recent decades [Serreze et al., 2000].

[52] Regarding the strong increase in May runoff for the Yenisey, higher spring temperatures should lead to earlier snowmelt. As summarized by Serreze et al. [2000], an 

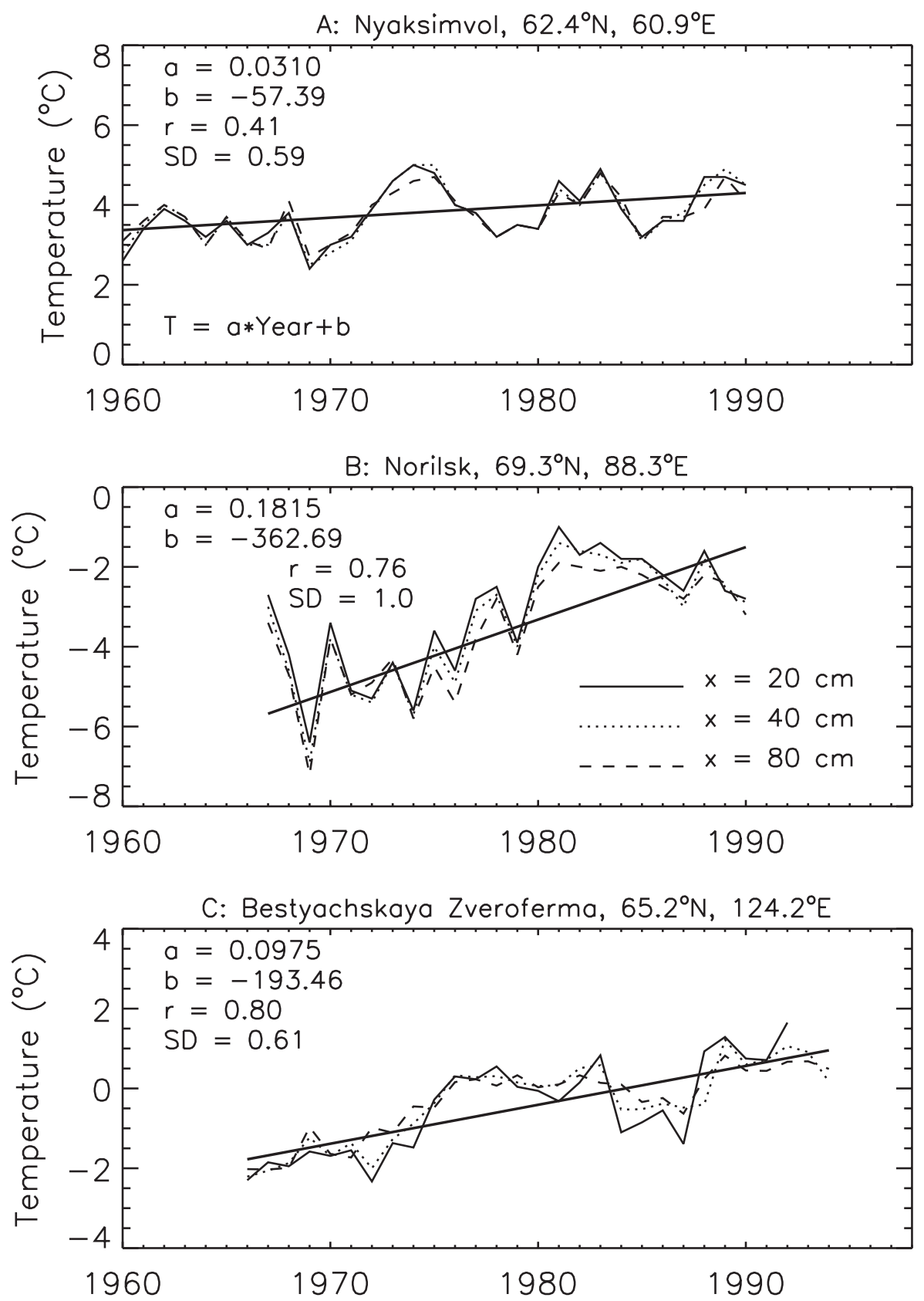

Figure 18. Mean annual ground temperatures at 20, 40 and $80 \mathrm{~cm}$ depth for stations Nyaksimvol $(\mathrm{Ob}$ basin) Norilsk (Yenisey basin) and Bestyachskaya Zveroferma (Lena basin). The trend lines are based on the average of temperatures at the three depths.

earlier loss of spring snow cover over Eurasia is supported from analysis of the weekly NOAA snow charts. Evaluated for either record length, there is also a small but significant increase in winter $P$ for the Yenisey. For the period 19601999 , the trend is $+14 \mathrm{~mm}$. This implies that the earlier loss of spring snow cover (due to higher temperatures) is allied with a deeper winter snowpack. Records summarized by Serreze et al. [2000] provide some support for this argument. The combination of a deeper winter snowpack and higher spring temperatures is consistent with the large increase in spring runoff. Note, however, that a positive winter $P$ trend is also found for the Lena with the shorter record, albeit only at the $90 \%$ confidence level. It is more difficult to explain the increased winter runoff. In the southern parts of the relatively warm $\mathrm{Ob}$ (see Figure 7a) higher temperatures might promote more frequent episodes of cold-season snowmelt and lead to more of the coldseason precipitation falling as rain. This explanation is less tenable for the colder Yenisey and Lena, where despite the observed warming trends, winter temperatures are still well below freezing.

[53] Another possibility is an increase in active layer thickness. Autumn freeze-up of the active layer would be delayed, contributing to more groundwater movement into river channels during autumn, seen as increased winter discharge. Some support is provided by Figure 18, which 

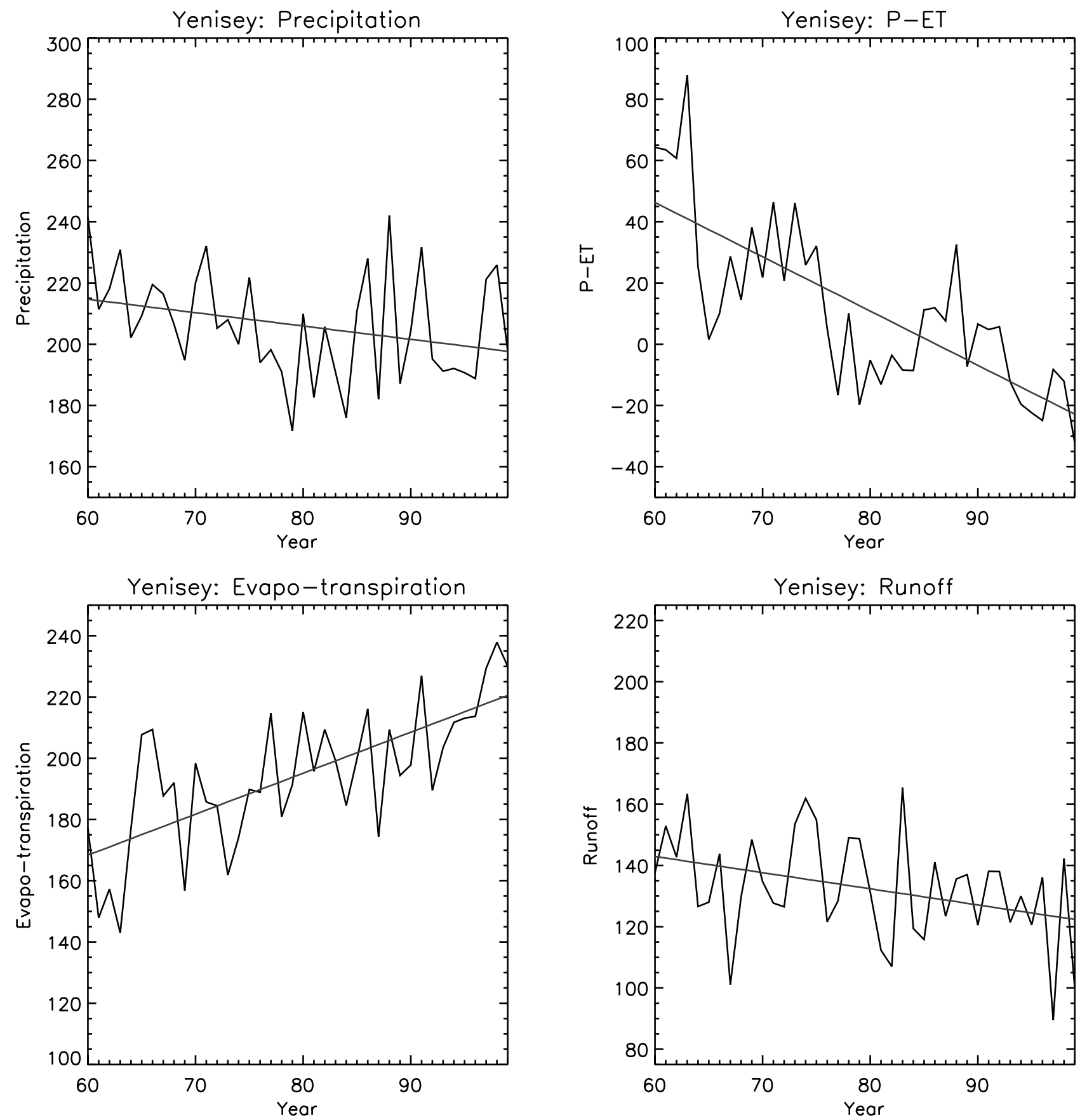

Figure 19. Summer (JJA) time series of $P, P$-ET and ET and $R(\mathrm{~mm})$ for the Yenisey basin with trend lines based on linear regression. ET is calculated as a residual from $P$ and $P-\mathrm{ET}$. For direct comparison of regression slopes, the $y$ axis for each variable has the same range $(150 \mathrm{~mm})$.

summarizes annual mean soil temperatures at $20 \mathrm{~cm}, 40 \mathrm{~cm}$ and $80 \mathrm{~cm}$ for the three stations outlined in section 2.4 located in the $\mathrm{Ob}$ (Nyaksimvol), Yenisey (Norilsk) and Lena (Bestyachskaya Zveroferma). Soil temperatures at each station exhibit large variability, but as evaluated over the available record length, there are significant positive trends at both Norilsk, (Yenisey basin) and Bestyachskaya Zveroferma, (Lena basin), largest for the site in the Yenisey basin for which the winter runoff increases have been largest. The lower temperatures at Norilsk as compared to Bestyachskaya Zveroferma (see the y axis) reflect latitude.
[54] Pavlov [1994] finds increases in near-surface (2-5 m) permafrost temperature for a number of sites in northern Russia from the 1970s through 1990. For the Marre-Sale station in Northwest Siberia, Pavlov [1996] reports that the rise in near surface permafrost temperature of $1-2^{\circ} \mathrm{C}$ is attended by an increase in active layer thickness exceeding $20 \%$. Comparisons between active layer thickness (for which relatively few measurements are available) and permafrost temperature are complicated as the former relate primarily to summer air temperature while the latter are more closely allied with mean annual air temperature [Romanov- 


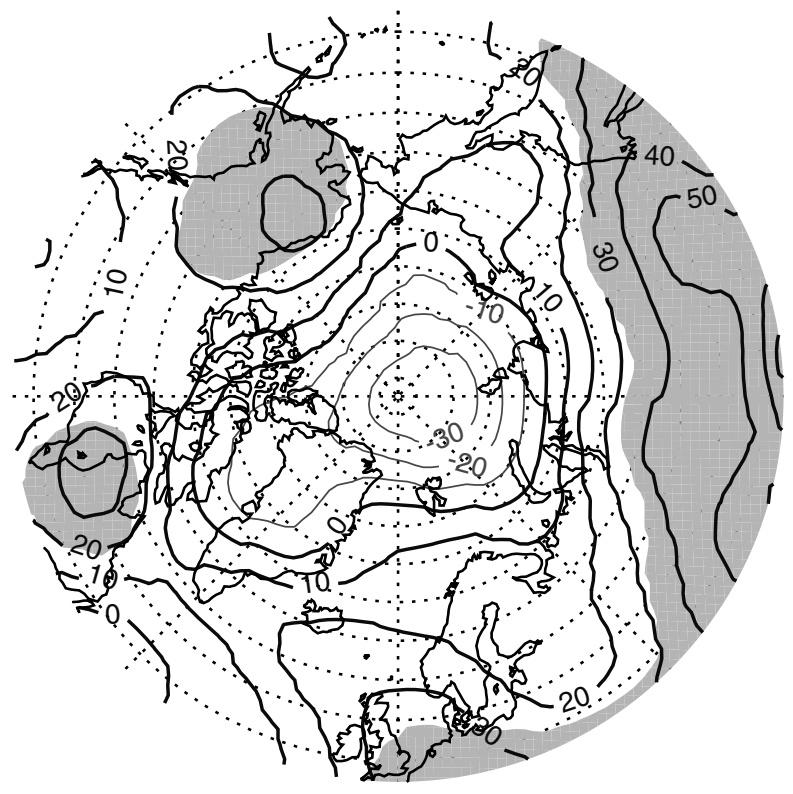

Figure 20. Linear trends of $500 \mathrm{hPa}$ height (geopotential meters) over the period 1960-1999 for summer. Positive trends are indicated by bold contours with negative trends indicated by light contours. Regions where the trends are significant (at least the 95\% level) are shaded.

sky and Osterkamp, 1997]. The trends surface air temperature over northern Russia for the past several decades are in turn much smaller in summer than for winter and spring [Serreze et al., 2001a]. While we consider Pavlov's results to provide some support for increased active later thicknesses, it is clearly premature to make definitive statements.

[55] The winter and spring runoff increases for the Yenisey are attended by reductions in runoff in summer and early autumn (Figure 17). These are not significant for individual months, but are for summer as a whole $(-21 \mathrm{~mm}$ over 1960-1999). The summer trends are also significant when evaluated for 1970 and onward. At face value, this can be attributed to the shift in the hydrograph peak toward earlier in the season (because of increased winter and spring runoff), perhaps partly countered by the increase in winter $P$. There is also some evidence of hydrograph shifts for the $\mathrm{Ob}$ and Lena. Results for the Mackenzie are difficult to interpret because of the shorter record.

[56] Summer time series of $P, P-\mathrm{ET}$ and ET suggest some additional influences in the Yenisey (Figure 19). The computed trends in $P$-ET and ET (both significant) are quite remarkable, indicative of strong drying. $P$-ET shows some indication of a decadal oscillation superimposed upon the trend. The total changes in $P-\mathrm{ET}$ and ET over 1960 1999 based on the regressions are $-71 \mathrm{~mm}$ and $+54 \mathrm{~mm}$. The strength of the summer changes in $P-\mathrm{ET}$ and ET argues for their reality, especially when considered in light of the attendant downward tendency in summer $P$ (significant at the $90 \%$ level). Further support is provided by the linear trends in $500 \mathrm{hPa}$ height for summer computed over 1960-1999 (Figure 20). The key feature is the statistically significant height increases over much of northern Eurasia. It was noted that summers with high $P-\mathrm{ET}$ in the Yenisey occur with a strong Urals trough with its axis roughly over the watershed. Low $P$-ET is likely when the $500 \mathrm{hPa}$ flow is more zonal, with positive height anomalies over the basin. The $500 \mathrm{hPa}$ trend is in accord with the inferred summer drying over the basin.

[57] Recall that annual runoff over 1960-1999 has increased in the Yenisey, indicating that the opposing monthly changes plotted in Figure 17 do not balance. At least in part, this may be a response to the increased winter precipitation. However, we speculate that if active layer thicknesses are indeed increasing, this could be allied with thawing of permafrost, providing an extra source of runoff. Recall that in the Yenisey, most of the permafrost is discontinuous, sporadic or isolated, compared to the colder Lena basin where continuous permafrost dominates. Permafrost in the Yenisey should be more sensitive to thawing. From this argument it is not clear, however, why no large runoff trends are observed for the Mackenzie, where strong increases in winter air temperature have also been observed.

[58] Finally, we examine summer averaged time series of the precipitation recycling ratio $\left(P_{\mathrm{m}} / P\right)$ for the same domains used in Figure 9. Results (Figure 21) are based on averaging $P_{\mathrm{m}} / P$ for June, July and August, the period for which the recycling ratio tends to be largest. Considering all four domains as a whole, the range between extremes of $P_{\mathrm{m}} / P$ is about 0.20 . Correlation analysis reveals that for the Eurasian domains, variability in the summer ratio is more closely tied to $\mathrm{F}+$ than to ET. Squared correlations for the Eurasian domains depicting inverse relationships between $P_{\mathrm{m}} / P$ and $\mathrm{F}+$ range from 0.69 to 0.79 (highest for the $\mathrm{Ob}$ ), while corresponding squared correlations depicting positive relationships with ET range from 0.18 to 0.36 , also highest for the Ob. For the Mackenzie domain, the squared correlations with F+ and ET are 0.49 and 0.63 , respectively. There are no significant trends in the summer precipitation recycling ratio.

\section{Summary and Conclusions}

[59] This paper examines the large-scale hydro-climatology of the terrestrial Arctic drainage system. Station data were used to compile monthly gridded time series of gaugecorrected precipitation $(P)$. Time series of precipitation minus evapotranspiration $(P-\mathrm{ET})$ were calculated from the moisture flux convergence, with estimates of ET obtained as a residual. Records of runoff were gleaned from gauge records near the river mouths.

[60] All basins exhibit a summer maximum in $P$ and summer minimum in $P-\mathrm{ET}$. Summer $P-\mathrm{ET}$ in the $\mathrm{Ob}$ is negative due to high ET rates. As computed for large domains in northern Eurasia, about $25 \%$ of July precipitation is of "local" origin in that it is associated with the recycling of water vapor evaporated within the domain. This points to a significant effect of the land surface on the summer hydrologic regime.

[61] For long-term water-year means (1 October through 30 September), $P$-ET for the Yenisey, Lena and Mackenzie is $16-20 \%$ lower than observed runoff. In the $\mathrm{Ob}$ the two values agree within $9 \%$. However, given the uncertainties in computed $P$-ET, we consider the atmospheric and surface water budgets to be reasonably well closed. Mean runoff 

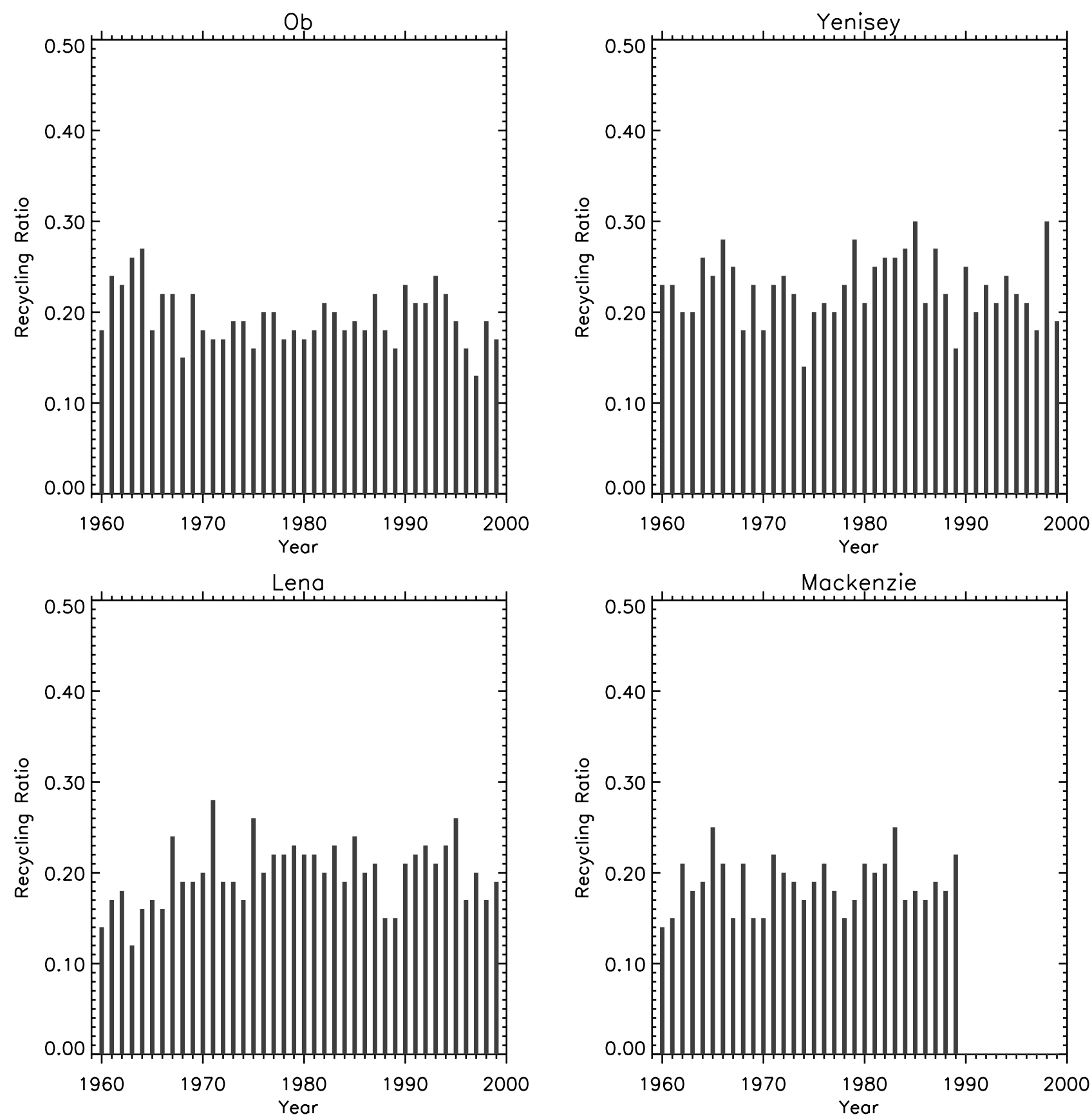

Figure 21. Summer (JJA) time series of the precipitation recycling ratio for the same regions used in Figure 9.

ratios $(R / P)$ in the colder and permafrost-dominated Yenisey, Lena and Mackenzie basins $(0.41-0.55)$ are higher than for the warmer and largely permafrost-free $\mathrm{Ob}(0.26)$. The mild conditions and lack of permafrost in the $\mathrm{Ob}$ are also seen in the large fraction of annual precipitation lost through ET (0.72-0.74).

[62] Regional anomalies in $P$-ET and $P$ tend to be strongly correlated in a positive sense. Year-to-year changes in these variables show generally clear associations with variability in the regional circulation. Relationships are especially well expressed for the $\mathrm{Ob}$, where for both summer and winter, variability in $P$-ET links to changes in the amplitude and phase angle of the Urals trough.
Squared correlations between monthly time series of $P-\mathrm{ET}$ ET and indices of the AO, NAO and other teleconnection patterns are generally weak.

[63] Our study points to a number of trends over the period 1960-1999. There are increases in winter runoff for the Lena and Yenisey, largest in the latter basin. The Yenisey has also seen an increase in winter precipitation, consistent with the sharp increase in spring runoff. Reductions in summer runoff for the Yenisey are seen as a shift in the hydrograph toward earlier in the season (in part countered by the increased winter precipitation). However, there is evidence from the $P$-ET and ET records of strong summer drying in this basin. The 
Yenisey has nevertheless experienced an increase in annual runoff. This is consistent with higher winter precipitation although we speculate a possible contributing role of thawing permafrost.

[64] There are many dangers in assessing hydrologic trends. Those based on atmospheric reanalysis should be treated with particular caution because of temporal changes in the amount and quality of assimilation data. Data from the new ERA-40 reanalysis are soon to come on line. With the anticipated improvements in data quality, some of the difficulties we discuss in closing the atmospheric and surface water budgets may be resolved. However, trend analysis will likely remain a problem. There are also continuing questions regarding the quality of available precipitation data sets, especially with respect to bias corrections. While discharge records are generally considered reliable, estimating winter discharge (when rivers are ice covered) is difficult and may impact on the winter trends that we calculate. Another issue is potential impacts on discharge associated with diversions and impoundments, in particular in the southern $\mathrm{Ob}$ and main stem of the Yenisey [Shiklomanov, 1995].

\section{Appendix A. Precipitation Data and Interpolation A1. Precipitation Data Sets}

[65] The first data set is an updated version of the Groisman et al. [1991] archive. It contains monthly time series for 622 stations in the FSU. Records are available through the early 1990 s for most stations and through the late 1990s for a smaller subset. During the 1940s and 1950s, the FSU changed from use of Nipher-shielded gauges to Tretiyakov gauges. From parallel measurements, a correction was adopted to adjust precipitation measured with the Nipher gauge to be comparable with the Tretiyakov values. All data used in our study (1960 onward) are based on measurements with the Tretiyakov gauge. To further improve homogeneity, corrections for wetting loss were adopted. The wetting loss is the portion of precipitation that sticks to the walls of the gauge after it is emptied. The station-specific wind corrections are a function of climatological wind speed, temperature, snowfall and precipitation intensity at the gauge site. We excluded those stations with missing wind correction values.

[66] The second archive is identified as National Climatic Data Center (NCDC) data set TD-9816 "Canadian Monthly Precipitation". The correction procedures are detailed by Groisman [1998]. The most recent records extend through 1990. The Canadian practice is to measure rainfall and snowfall separately. Rainfall is measured at gauges. At the majority of stations, a ruler is used to measure the depth of freshly fallen snow, which is converted into water equivalent using a constant 10:1 ratio. Starting in the early 1960s, some stations were equipped with Nipher-shielded elevated snow gauges that directly measure the water equivalent of snow [Groisman and Easterling, 1994]. Climatological ratios were computed between the water equivalent directly measured at Nipher gauges and estimated from the ruler measurements. These ratios were adjusted to account for average snow undercatch at the Nipher gauges and then interpolated to the station locations. The interpolated ratios were then multiplied by the water equivalent at the stations determined by the 10:1 ruler conversions. Corrections are also made for wetting losses.

[67] The two data sets just described provide coverage over all of the Arctic drainage except for Alaska, Greenland and northern Europe. For these areas, we use data from the Global Historical Climatological Network (GHCN) archive [Vose et al., 1992]. Gauge undercatch due to winds and biases from evaporation from the gauges and wetting losses were adjusted through local interpolation of the Legates and Willmott [1990] correction factors (provided on a $0.5 \times 0.5$ degree grid) to the station locations. Coverage for Eurasia was further improved with an additional 105 stations for the years 1966-1990 within the Ob, Yenisey and Lena basins obtained through collaboration with V. Vuglinsky (State Hydrometeorological Institute, St. Petersburg, Russia). These data were also adjusted using Legates and Willmott corrections.

\section{A2. Interpolation of Precipitation Data}

[68] The station data were interpolated to the EASE grid using a modified version of the Shepard [1968] scheme. The software was developed at the Department of Geography, University of Delaware [Willmott et al., 1985]. The Shepard algorithm is an inverse distance interpolation. Values are defined for the maximum (MAX) and minimum (MIN) number of data points (i.e., station precipitation values) to be used in the interpolation to an EASE grid. An initial search radius around each grid point is defined from the area of the spatial domain to be interpolated to and the number of available data points (stations). If the number of data points within the search radius exceeds MAX, the closest data points up to MAX are used in the interpolation. If there are fewer than MIN data points in the search radius, the radius is expanded until at least MIN values are found. The interpolator uses spherical geometry to calculate distances, accounts for uneven clustering ("clumpiness") of station distributions and allows for extrapolation beyond the range of data.

[69] Tests were conducted to determine the optimal number of stations to be used in the interpolation (the values of MAX and MIN). These tests were based on assessments of the absolute mean interpolation error averaged over all stations, using as input the long-term monthly station means. At each station, an interpolation error was found by holding that station out of the data set and interpolating a value at that location from surrounding stations. MIN and MAX values of 5 and 15 were found to provide the lowest absolute mean interpolation errors. These mean errors range from $8.7 \mathrm{~mm}$ in July to $14.6 \mathrm{~mm}$ in December. The higher errors in winter arise from the combination of high precipitation values and sparse data coverage around coastal Greenland.

[70] Acknowledgments. This study was supported by the National Science Foundation under the Arctic System Science (ARCSS) program grants OPP-9732461, OPP-9910315, OPP-9907541, OPP-9906906 and NASA grants NAG5-6820 and NAG5-9568.

\section{References}

Aagaard, K., and E. C. Carmack, The role of sea ice and other fresh waters in the Arctic circulation, J. Geophys. Res., 94(C10), 14,485-14,498, 1989. 
Alestalo, M., The atmospheric water vapor budget over Europe, in Variations in the Global Water Budget, edited by A. Street-Perrott, M. Beran, and R. Ratcliffe, pp. 67-79, D. Reidel, Norwell, Mass., 1983.

Armstrong, R. L., and M. J. Brodzik, An earth-gridded SSM/I data set for cryospheric studies and global change monitoring, Adv. Space Res., 16, $155-163,1995$

Bjornsson, H., L. A. Mysak, and R. Brown, On the interannual variability of precipitation and runoff in the Mackenzie drainage basin, Clim. Dyn., 12, 67-76, 1995

Bowling, L. C., D. P. Lettenmaier, and B. V. Matheussen, Hydroclimatology of the Arctic drainage basin, in The Freshwater Budget of the Arctic Ocean, edited by E. L. Lewis et al., pp. 57-90, Kluwer Acad., Norwell, Mass., 2000.

Broecker, W. S., hermohaline circulation, the Achilles heel of our climate system: Will man-made $\mathrm{CO}_{2}$ upset the current balance?, Science, 1582 1588, 1997.

Brown, J., O. J. Ferrians Jr., J. A. Heginbottom, and E. S. Melnikov, International permafrost association circum-Arctic map of permafrost and ground ice conditions, U.S. Geol. Surv. Circum-Pac. Map Ser., Map CP-45, 1997 (for sale by the U.S. Geological Survey, Information Services, Box 25286, Federal Center, Denver, CO 80225).

Brown, J., O. J. Ferrians Jr., J. A. Heginbottom, and E. S. Melnkov, Digital circum-Arctic map of permafrost and ground-ice conditions, in Circumpolar Active-Layer Permafrost System (CAPS), Version 1.0, International Permafrost Association, Data and Information Working Group, comp., University of Colorado, Boulder, Colo., 1998.

Brubaker, K. L., D. Entekhabi, and P. S. Eagleson, Estimation of continental-scale precipitation recycling, J. Clim., 6, 1077-1089, 1993

Cressman, G. P., An operational objective analysis system, Mon. Weather Rev., 87(10), 367-374, 1959.

Cullather, R. I., D. H. Bromwich, and M. C. Serreze, The atmospheric hydrologic cycle over the Arctic basin from reanalyses. Part I: Comparison with observations and previous studies, J. Clim., 13, 923-937, 2000.

Eltahir, E. A. B., and R. L. Bras, Precipitation recycling in the Amazon Basin, Q. J. R. Meteorol. Soc., 120, 861-880, 1994.

Eltahir, E. A. B., and R. L. Bras, Precipitation recycling, Rev. Geophys., 34(3), 367-378, 1996

Gilichinsky, D. A., R. G. Barry, S. S. Bykhovets, V. A. Sorokovikov, T. Zhang, S. L. Zudin, and D. G. Fedorov-Davydov, A century of temperature observations of soil climate: Methods of analysis and long-term trends, in Proceedings of the 7th International Conference on Permafrost, Yellowknife, Canada, June 22-27, pp. 313-317, 1998.

Goodison, B. E., P. Y. T. Louie, and D. Yang, WMO solid precipitation measurement intercomparison, Final Rep., WMO TD-No. 872, 212 pp., World Meteorol. Organ., Geneva, 1998.

Grabs, W. E., F. Portman, and T. de Couet, Discharge observation networks in Arctic regions: Computation of the river runoff into the Arctic Ocean, its seasonality and variability, in The Freshwater Budget of the Arctic Ocean, edited by E. L. Lewis et al., pp. 249-267, Kluwer Acad., Norwell, Mass., 2000.

Groisman, P. Y., National Climatic Data Center Data Documentation for TD-9816, Canadian Monthly Precipitation, National Climate Data Center, Asheville, N. C., 21 pp., 1998.

Groisman, P. Y., and D. R. Easterling, Variability and trends of precipitation and snowfall over the eastern United States and Canada, J. Clim., 7 $184-205,1994$

Groisman, P. Y., V. V. Koknaeva, T. A. Belokrylova, and T. R. Karl, Overcoming biases of precipitation: A history of the USSR experience, Bull. Am. Meteorol. Soc., 72, 1725-1733, 1991.

Hinzman, L. D., D. L. Kane, C. S. Bensen, and K. R. Everett, Energy balance and hydrological processes in an Arctic watershed, Ecol. Stud., 120, 131-154, 1996.

International Permafrost Association (IPA), Circumpolar Active-Layer Permafrost System (CAPS), Version 1.0, Data and Information Working Group, University of Colorado at Boulder, Boulder, Colo., 1998.

Kalnay, E., et al., The NCEP/NCAR 40-year reanalysis project, Bull. Am. Meteorol. Soc., 77, 437-471, 1996.

Kane, D. L., L. D. Hinzman, C. S. Bensen, and G. E. Liston, Snow hydrology of a headwater Arctic basin, 1, Water Resour. Res., 27, 1099-1109, 1991.

Kistler, R., et al., The NCEP-NCAR 50-year reanalysis: Monthly means CD-ROM and documentation, Bull. Am. Meteorol. Soc., 82, 247-267, 2001.

Lackmann, G. M., and J. R. Gyakum, The synoptic and planetary-scale signatures of precipitating systems over the Mackenzie River Basin, Atmos. Ocean, 34, 647-674, 1996.

Lammers, R. B., A. I. Shiklomonov, C. J. Vorosmarty, B. M. Fekete, and B. J. Peterson, Assessment of contemporary Arctic river runoff based on observational records, J. Geophys. Res., 106(D4), 3321-3334, 2001.
Legates, D. R., and C. J. Willmott, Mean seasonal and spatial variability in gauge-corrected, global precipitation, Int. J. Climatol., 10, 111-127, 1990.

McDonald, R. W., E. C. Carmack, F. A. McLaughlin, K. K. Falkner, and J. H. Swift, Connections among ice, runoff and atmospheric forcing in the Beaufort Sea, Geophys. Res. Lett., 26, 2223-2226, 1999.

Misra, V., M. K. Yau, and N. Badrinath, Atmospheric water species budget in mesoscale simulations of lee cyclones over the Mackenzie River Basin, Tellus, 52A, 140-161, 2000.

Oechel, W. C., S. J. Hastings, G. Vourlitis, M. Jenkins, G. Richers, and N. Guilke, Recent change of Arctic tundra ecosystems from a net carbon dioxide sink to a source, Nature, 361, 520-523, 1993.

Pavlov, A. V., Current changes of climate and permafrost in the arctic and sub-arctic of Russia, Permafr. Periglac. Process., 5, 101-110, 1994.

Pavlov, A. V., Permafrost-climatic monitoring of Russia: Analysis of field data and forecast, Polar Geogr. Geol., 20, 44-64, 1996.

Robinson, D. A., K. F. Dewey, and R. R. Heim, Global snow cover monitoring: An update, Bull. Am. Meteorol. Soc., 74, 1689-1696, 1993.

Rogers, A. N., D. H. Bromwich, E. N. Sinclair, and R. I. Cullather, The atmospheric hydrologic cycle over the Arctic Basin fron reanalyses, 2, Interannual variability, J. Clim., in press, 2001.

Romanovsky, V. E., and T. E. Osterkamp, Thawing of the active layer on the coastal plain of the Alaskan Arctic, Permafr. Periglac. Process., 8, $1-$ 22, 1997.

Semiletov, I. P., N. I. Savelieva, G. E. Weller, I. I. Pipko, S. P. Pugach, A. Yu Gukov, and L. N. Vasilevskaya, The dispersion of Siberian river flows into coastal waters: Meteorological, hydrological and hydrochemical aspects, in The Freshwater Budget of the Arctic Ocean, edited by E. L. Lewis et al., pp. 323-366, Kluwer Acad., Norwell, Mass., 2000.

Serreze, M. C., and C. M. Hurst, Representation of mean Arctic precipitation from NCEP-NCAR and ERA reanalyses, J. Clim., 13, 182-201, 2000.

Serreze, M. C., R. G. Barry, and J. E. Walsh, Atmospheric water vapor characteristics at $70^{\circ} \mathrm{N}, \mathrm{J}$. Clim., 8, 719-731, 1995.

Serreze, M. C., J. E. Walsh, F. S. Chapin III, T. Osterkamp, M. Dyurgerov, V. Romanovsky, W. C. Oechel, J. Morison, T. Zhang, and R. G. Barry, Observational evidence of recent change in the northern high-latitude environment, Clim. Change, 46, 159-207, 2000.

Serreze, M. C., A. H. Lynch, and M. P. Clark, The Arctic frontal zone as seen in the NCEP/NCAR reanalysis, J. Clim., 14, 1550-1567, 2001a.

Shepard, D., A two-dimensional interpolation function for irregularlyspaced data, in Proceedings-1968 ACM National Conference, pp. 517-524, 1968 .

Shiklomanov, I. A., Estimate of the change in the Yenisey river inflow to the Kara Sea as affected by industrial activities in its basin, in Nature Conditions of the Kara and Barents Seas (in Russian), Meteorol. and Hydrol. Publ. Cent., Moscow, Russia, 1995.

State Committee of the USSR for Hydrometeorology and Environmental Control, Instructions for Meteorological Stations and Posts, vol. 3, 1, Meteorological Observations at Stations, Gidrometeozdat, Leningrad, 1985

Steele, M., and T. Boyd, Retreat of the cold halocline layer in the Arctic Ocean, J. Geophys. Res., 103, 10,419-10,435, 1998.

Thompson, D. W. J., and J. M. Wallace, The Arctic Oscillation signature in the wintertime geopotential height and temperature fields, Geophys. Res. Lett., 25, 1297-1300, 1998.

Thompson, D. W. J., and J. M. Wallace, Annual modes in the extratropical circulation, 1, Month-to-month variability, J. Clim., 15, 1000-1016, 2000

Trenberth, K. E., Atmospheric moisture residence times and cycling: Implications for rainfall rates and climatic change, Clim. Change, 39, 667694, 1998

Vorosmarty, C. J., B. Fekete, M. Meybeck, and R. B. Lammers, The global system of rivers: Its role on organizing continental landmass and defining land-to-ocean linkages, Global Biogeochem. Cycles, 14, 599-621, 2000.

Vose, R. S., R. L. Schmoyer, P. M. Steurer, T. C. Peterson, R. Heim, T. R. Karl, and J. Eischeid, The global historical climatology network: Longterm monthly temperature, precipitation, sea level pressure, and station pressure data, Tech. Rep., ORNL/CDIAC-53, NDP-041, Carbon Dioxide Inf. Anal. Cent., Oak Ridge Natl. Lab., Oak Ridge, Tenn., 1992.

Walsh, J. E., X. Zhou, D. Portis, and M. C. Serreze, Atmospheric contribution to hydrologic variations in the Arctic, Atmos. Ocean, 34, 733-755, 1994.

Willmott, C. J., and S. M. Robeson, Climatologically Aided Interpolation (CAI) of terrestrial air temperature, Int. J. Climatol., 15, 221-229, 1995.

Willmott, C. J., C. M. Rowe, and W. D. Philpot, Small-scale climate maps: A sensitivity analysis of some common assumptions associated with gridpoint interpolation and contouring, Am. Cartogr., 12, 5-16, 1985.

Yang, D., B. Goodison, J. Metcalfe, P. Louie, E. Elomaa, C. Hanson, 
V. Golubev, T. Gunther, J. Milkovic, and M. Lapin, Compatability evaluation of national precipitation gauge measurements, J. Geophys. Res. 106(D2), 1481-1491, 2001.

Yang, D., D. Kane, L. Hinzman, and X. Zhange, Major Siberian river discharge regime and change, J. Geophys. Res., 107, doi:10.1029/ 2002JD002542, in press, 2002.

Zhang, T., Roger G. Barry, K. Knowles, J. A. Heginbottom, and J. Brown, Statistics and characteristics of permafrost and ground ice distribution in the Northern Hemisphere, Polar Geogr., 23, 147-169, 1999.

Zhang, T., R. G. Barry, D. Gilichinsky, S. S. Bykhovets, V. A. Sorokovikov, and J. Ye, An amplified signal of climatic change in soil temperatures during the last century at Irkutsk, Russia, Clim. Change, 49(1-2), 4176, 2001.

D. H. Bromwich, Byrd Polar Research Center, Ohio State University, Columbus, OH, USA.

M. P. Clark, A. J. Etringer, M. C. Serreze, and T. Zhang, Cooperative Institute for Research in Environmental Sciences, University of Colorado, Campus Box 449, Boulder, CO 80309-0449, USA.

R. Lammers, Water Systems Analysis Group, University of New Hampshire, Durham, NH, USA. 